\title{
Contrast and Synergy between Electrocatalysis and Heterogeneous Catalysis
}

\author{
Andrzej Wieckowski ${ }^{1}$ and Matthew Neurock ${ }^{2}$ \\ ${ }^{1}$ Department of Chemistry, University of Illinois at Urbana-Champaign, Urbana, IL 61801, USA \\ ${ }^{2}$ Departments of Chemical Engineering and Chemistry, University of Virginia, Charlottesville, VA 22904-4741, USA
}

Correspondence should be addressed to Matthew Neurock, mn4n@virginia.edu

Received 27 May 2011; Accepted 27 July 2011

Academic Editor: Wolfgang Schmickler

Copyright (C) 2011 A. Wieckowski and M. Neurock. This is an open access article distributed under the Creative Commons Attribution License, which permits unrestricted use, distribution, and reproduction in any medium, provided the original work is properly cited.

\begin{abstract}
The advances in spectroscopy and theory that have occurred over the past two decades begin to provide detailed in situ resolution of the molecular transformations that occur at both gas/metal as well as aqueous/metal interfaces. These advances begin to allow for a more direct comparison of heterogeneous catalysis and electrocatalysis. Such comparisons become important, as many of the current energy conversion strategies involve catalytic and electrocatalytic processes that occur at fluid/solid interfaces and display very similar characteristics. Herein, we compare and contrast a few different catalytic and electrocatalytic systems to elucidate the principles that cross-cut both areas and establish characteristic differences between the two with the hope of advancing both areas.
\end{abstract}

\section{Introduction}

Electrocatalysis and heterogeneous catalysis are closely related in that they involve well-controlled sequences of elementary bond-breaking and making processes and share many common mechanistic principles in the transformation of molecules over supported metal and metal oxide catalysts. While there are many areas of synergy between the two, including the materials that are used and the available reaction pathways and mechanisms, there are also wellestablished differences [1-4]. Heterogeneous catalysis has often celebrated more detailed insights into reaction mechanisms than electrocatalysis due to the advances in spectroscopy and theory of the gas/solid interface as compared to the more complex aqueous/solid interface in electrocatalysis. As such electrocatalysis has often followed from the mechanistic advances derived from gas phase heterogeneous catalysis. Many of the current efforts in heterogeneous catalysis, however, are focused on energy conversion strategies involving catalytic transformations which proceed at the fluid/ solid interface and, as a consequence, are now closely following the leads from electrocatalysis. A number of common mechanistic principles and features are beginning to emerge between the two fields. Understanding the synergies as well as the differences between catalysis and electrocatalysis should thus enable advances in the science and application for both areas. Herein, we compare and contrast some of the fundamental mechanistic constructs as well as the practical applications for electrocatalysis and heterogeneous catalysis. More specifically, we focus on metal catalyzed oxidation processes.

\section{General Comparisons between Catalysis and Electrocatalysis}

At the macroscopic level, many of the catalytic materials that are used in catalysis and electrocatalysis are very similar in that they involve supported metal particles, where the interaction between the metal and support is critical to catalyst performance as well as catalyst stability. The metal or metal oxide/support interface can result in sites with unique structural or electronic characteristics, novel bifunctional sites, and/or sites that promote proton and electron transfer. The nature and the strength of the bonds between the metal and the support control the stability of these materials and their resilience to harsh reaction environments.

The characterization of the electronic and atomic structure of the metal and the support in both catalysis as well 
as electrocatalysis is typically carried out through the use of extended X-ray absorption spectroscopy (XAFS), electron microscopy, X-ray (XPS) and ultraviolet photoelectron spectroscopy (UPS). In addition, many of the most active metals used in electrocatalysis are very often the same as those used in heterogeneous catalysis. For example, $\mathrm{Pt}$ and other group VIII metals are known to be very active in the electrocatalytic oxidation of alcohols and the reduction of oxygen in fuel cells, automotive exhaust catalysis and hydrogenolysis, and hydrogenation catalysis in the conversion of petroleum and renewable resources. This is predominantly the result of the well-established Sabatier's Principle which suggests that the metals in middle of the periodic table demonstrate an optimal metal-adsorbate bond strengths necessary to balance surface reaction steps and product desorption steps [5-9].

In addition to similarities, there are well-established differences between traditional gas phase heterogeneous catalysis and electrocatalysis. Perhaps the greatest difference between the two relates to the unique reaction environments in which they are carried out. The gas phase catalytic environment is far less complex than that of the electrified water/metal interface for electrocatalytic systems, thus allowing for more detailed spectroscopic characterization of the working surface intermediates, application of ultrahigh vacuum experiments as well as direct comparisons with theoretical simulations on model surfaces. The presence of solution, ions, charged interfaces, complex surface potentials, and electric fields present in electrocatalytic systems can all act to significantly change the surface chemistry and catalysis that occurs in these environments. These interfaces tend to significantly promote polar reactions and direct heterolytic bond activation steps which would otherwise be unstable and not occur in gas phase catalytic systems. The electrochemical environment, however, is typically much harsher and deleterious to catalyst stability than that found in gas phase catalysis. The dissolution of the metal and the support are thus important concerns for electrocatalytic processes as these steps are enhanced under electrochemical conditions. In addition, the presence of electrolyte often enhances or impedes catalytic kinetics and within certain potential regions can result in poisoning of the surface.

While there are important differences between electrocatalysis and catalysis that result from the presence of solution, counter ions, and electric fields, Nørskov [8-12], Anderson [13-18], and others $[1,6]$ have been able to model the electrochemical systems by simply carrying out gas phase calculations on well-defined model clusters and surfaces and adding in the critical features that influence the surface chemistry such as local water molecules as well as the influence of potential. This is an important step in that one has the ability to not only understand but begin to tune the reaction chemistry. Understanding the similarities and differences of the molecular transformations that occur at ultrahigh vacuum conditions and electrochemical conditions will undoubtedly drive advances in the development of catalytic and electrocatalytic materials and processes.

In addition to the scientific issues, there are also a number of important technological differences in the "infrastructure" that supports the heterogeneous and electrocatalysis communities. Most of electrocatalysis appears to be centered around fuel cells and more specifically proton exchange membrane (PEM) fuel cells carry out the oxidation of hydrogen, oxygenates, or hydrocarbon molecules to $\mathrm{CO}_{2}$ and the reduction oxygen to water [19]. This is in clear contrast to heterogeneous catalysis, which spans a wide and diverse range of different molecules with very rich chemistry and stands behind extensive chemical, automotive, petroleum, and pharmaceutical industries. In addition, there have been significant research and development investments in heterogeneous catalysis from the government as well as industry. Methane reforming, methane combustion, ammonia synthesis $\mathrm{NO}_{\mathrm{x}}$ conversion, and Fischer Tropsch synthesis, for example, are very large-scale processes which have no analogue in electrocatalysis. Furthermore, the future directions for PEM fuel cell catalysis is very specific with a strong focused effort on resolving the issues related to durability and maintaining catalytic activity for many years. This is quite different than the shorter lifetimes involved in most heterogeneous catalytic processes with the exception of automotive emission catalysis. In electrocatalysis, catalyst must be able to withstand the harsh operating conditions and operate effectively over the lifetime of the vehicle. Catalyst loss and deactivation tend to be quite severe in electrocatalysis due to the presence of solution, ions, and electric fields which not only lead to catalyst poisoning but also catalyst dissolution. This significantly limits the choice of catalytic materials to specific supported metals/alloys, metal oxides, and other stable inorganic materials such as chalcogenides or carbides. This is a very narrow range of possibilities as compared to what is typically practiced in the gas phase heterogeneous catalysis community. The long term durability, aggressive solution conditions (both high and low $\mathrm{pH}$ ), as well as the cost tend to prevent other avenues available to gas phase catalysis to be applied in the field of electrocatalysis.

Despite the complexity and the challenges of the electrochemical environment and the differences outlined above, many of the fundamental constructs that govern gas phase catalysis are also integral to electrocatalysis. There have been a number of pioneering developments in spectroscopy, kinetic analyses, theory, and synthesis that have occurred over the past few decades that have clearly shown how traditional concepts from heterogeneous catalysis apply directly to electrocatalysis. This includes the elucidation of nature of the active site, competitive adsorption phenomena, the influence of alloys, promoters and poisons, structure sensitivity, surface oxidation state, particle size effects, and metal support interactions. A schematic representation of the complex metal solution interface that would exist in either the catalytic or electrocatalytic oxidation of glucose over a carbon-supported PtRu alloy cluster is shown in Figure 1. In a review that is now over ten years old, Jarvi and Stuve [20] elegantly described the direct link between some of the fundamental principles that control heterogeneous catalysis and electrocatalysis. This included the specific accounting of active sites, the identification of reaction intermediates in elucidating reaction mechanisms, and the role of poisons and modifiers and their influence on catalytic kinetics and aging. The authors nicely showed that the kinetics for catalysis and 


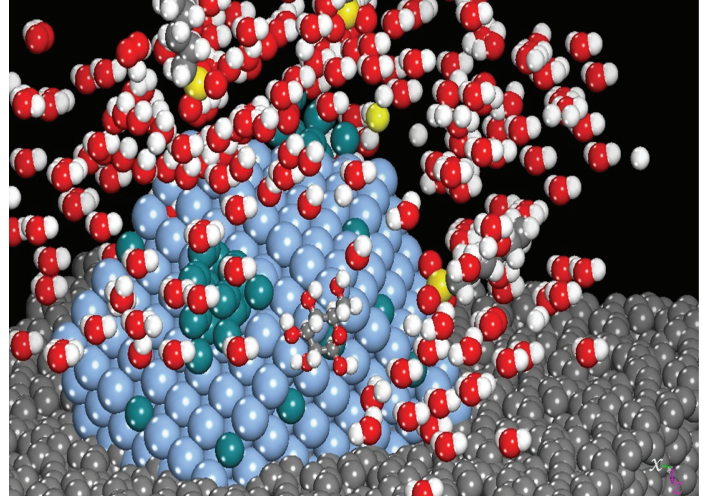

FIGURE 1: Schematic representation of the complex aqueous/metal interface involved in the catalytic and electrocatalytic oxidation of glucose over a PtRu alloy particle supported on carbon in the presence of electrolyte.

electrocatalysis were essentially the same and shared a common framework.

The complexity of the aqueous/metal interface and the inability to spectroscopically resolve molecular intermediates at this interface limited early electrocatalytic studies to measurements of macroscopic kinetics with little understanding of the elementary molecular transformations, the active sites or the influence the atomic and the electronic structure. This put electrocatalysis at a distinct disadvantage over traditional gas phase heterogeneous catalysis. The tremendous breakthroughs that have occurred over the past two decades in the ability to characterize the atomic structure of the working surface and reaction intermediates on the surface within the electrochemical environments have made it possible to begin to discuss elementary mechanisms and the influence of specific structural and composition parameters. Breakthroughs in broad-band spectroscopy [21], in situ electrochemical NMR [22-24], EXAFS [25-29], and surface-enhanced infrared spectroscopy $[30,31]$ are helping to significantly advance our understanding of electrocatalysis and in some cases begin to rival that in gas phase catalysis. These methods now allow for the direct insights into the nature of the active sites as well as surface intermediates under actual working conditions. Such insight has led to an exponential growth in the literature in the identification of active sites, reaction mechanisms, and rigorous structure-property relationships. Despite these important advances, the molecular resolution of intermediates under working conditions still presents a significant challenge and as such has been limited to only a few different intermediates and systems. In addition, these methods provide information on model systems that lack the complexity of the actual catalytic environment and often provide only a limited understanding.

In addition to these advances in spectroscopy, the past two decades have witnessed exponential increases in computational power and tremendous advances in theory and simulation methods. The development of density functional theory along with higher level ab initio wave function methods, and novel embedding methods, for example, has revolutionized our understanding adsorbate bonding and reactivity on well-defined surfaces and organometallic clusters. Due to limited computational resources, methods, and knowledge, most of these initial theoretical studies were focused on modeling ideal single-crystal surfaces under vacuum conditions. The insights and confidence gained from these initial efforts together with further increases in computational methods and nurturing from the experimental electrocatalysis community have helped to "seed" the exponential growth that has occurred in the development and the application of theory in electrocatalysis over the past ten years. Many of the initial developments were based on important insights into the electronic factors that controlled electrocatalytic reactivity. Andserson pioneered the development of reaction center model [13, 15, 18, 32-35], whereas Nørkov and colleagues $[11,12]$ developed a simple but elegant method that directly relates gas phase surface reaction energies to reaction energies at applied potentials. Schmickler et al. [3638] developed a model Hamiltonian that appropriately captures bond-breaking and bond-making processes that occur over metal surfaces in electrochemical systems by combining fundamental electron transfer and solvent reorganization principles derived from Marcus theory, Newns Anderson theory on surface reactivity, and a tight binding theory.

These initial efforts were subsequently followed by $a b$ initio-based simulation methods to follow chemistry within the aqueous metal interface and the direct relationship to electrocatalysis at applied potentials. There are now a number of rather sophisticated models that include the presence of solution, electrochemical potentials, applied fields, and actual electrolyte in modeling the electrocatalysis. Filhol, Taylor, and Neurock used explicit electrolyte or charge to establish the double layer at the surface [39-43]. The charged surfaces were then referenced to vacuum in order to establish the working potential. Otani et al. used DFT to describe the water metal interface and coupled this with an effective screening medium to represent to polarizable continuum $[44,45]$. Jionnouchi and Anderson developed a similar approach by combined density functional theory and modified Poisson-Boltzmann theory [46]. Rossmeisl et al. [47] used explicit protons at the water/metal interface to establish the double-layer interface. While the models by Neurock, Otani, Anderson, and Nørskov differ in how they treat the double layer, they are providing more rigorous solutions to the electrochemical transformations that occur on electrode surfaces. It is important, however, to note that these approaches are at best semiquantitative due to limitations of fundamental accuracy of the quantum mechanical methods, modeling electron transfer reactions and simulating long time dynamics, the full reaction environment, or the millions of configurations needed for accurate statistical treatments. Vapor phase density functional calculations of bond energies and activation barriers are typically within the range of $0.1-$ $0.2 \mathrm{eV}$ accuracies but can have outliers $[2,48]$. The simulation of electrochemical systems would at best only be $0.3 \mathrm{~V}$. Despite these issues, theory has plaid and will likely continue to play a very valuable role in understanding and establishing trends.

The discussions that follow will look to theory only to provide insights rather than quantitative predictions. All of 
the simulations reported were carried out gradient corrected periodic DFT calculations using the Vienna Ab Initio Simulation Program (VASP) $[49,50]$ with four-layer metal slabs in the presence of solution, where the bottom two layers in the metal were held fixed to the bulk lattice positions of the metal. The coordinates of the metal atoms in the top two layers along with all of the atoms in the adsorbates as well as in the solution layer were fully optimized. Transition states were isolated using the nudged elastic band method with climbing $[51,52]$ followed by the dimer method [53]. The specific details are reported in the previous papers [3943].

Rather than continue to discuss the obvious connections between electrocatalysis and gas phase heterogeneous catalysis, it is perhaps more interesting to discuss the growing efforts for carrying out heterogeneous catalysis in solution and new and emerging results that connect heterogeneous catalysis to well-established principles and phenomena in electrocatalysis. There has been an exponential growth over the past few years in carrying out heterogeneous catalytic reactions in solvents or aqueous media. This has been the result of the significant efforts to convert biomass into chemicals and fuels [54-59]. The carbohydrates that result from the breakdown of biomass are soluble in aqueous media and in addition can be catalytically converted at lower temperatures and much milder conditions than traditional gas phase processes. Similarly, many of the processes used in the selective hydrogenation and selective oxidation of fine chemical and pharmaceutical intermediates are also carried out in aqueous or solvent media that operate at lower temperatures to control both chemical as well as enantiomeric selectivities. Many of the catalyst performance and durability issues found in these systems have strong parallels to those found in electrocatalysis. Despite the similarities, there have been very few attempts to connect or compare the two.

\section{Specific Comparisons between Catalysis and Electrocatalysis: Example Systems}

3.1. Metal Support Interface. Before discussing specific chemistry, we will first focus the metal-support interface in aqueous phase heterogeneous catalysis and electrocatalysis. While the lower temperatures used in aqueous phase catalysis help to control the reaction selectivity, the presence of water often leads to the hydrolysis of metal support bonds which can significantly limit the supports that can be used due to issues related to metal sintering and dissolution. Much of the initial work in the area of conversion of biorenewables was carried out over traditional transition metal catalysts $(\mathrm{Pd}$, $\mathrm{Ru}, \mathrm{Pt}$, and $\mathrm{Ni}$ ) and their supports including $\mathrm{SiO}_{2}, \mathrm{Al}_{2} \mathrm{O}_{3}$, $\mathrm{TiO}_{2}$, and high surface area carbons in order to identify active and selective materials $[54-57,60]$. There was little emphasis on the fundamental surface chemistry that occurred in the solution phase or the stability of these materials. Maris et al. $[61,62]$ were some of the first to identify the potential issues related to metal-support interactions under aqueous phase catalytic conditions. They showed that while Ru supported on $\mathrm{SiO}_{2}$ leads to $100 \%$ selective hydrogenation of glucose to the sugar alcohol, the catalyst used was inherently unstable in aqueous media and resulted in the significant metal particle growth. Subsequent studies by Ketchie et al. [63] used in situ X-ray absorption spectroscopy to monitor the oxidation state of the $\mathrm{Ru}$ and follow the metal stability over a range of traditional supports including $\mathrm{SiO}_{2}, \gamma-\mathrm{Al}_{2} \mathrm{O}_{3}$, carbon, and $\mathrm{TiO}_{2}$. Significant sintering of $\mathrm{Ru}$ on both $\mathrm{SiO}_{2}$ and $\mathrm{Al}_{2} \mathrm{O}_{3}$ supports occurred at the mild conditions associated with the conversion of biorenewables. Both the high surface area activated carbon and titania, on the other hand, were found to be stable supports for aqueous phase catalysis over a range of operating conditions. They showed that different carbons may behave differently and that great care must be taken to elucidate the nature of the metal-support interactions under actual process conditions. Most of the recent studies on the conversion of renewables as well as the hydrogenation of pharmaceutical intermediates are now carried out on activated high surface area carbon due to the stability issues.

Interestingly, many of these issues were resolved in the electrocatalysis community many years earlier as metal dissolution is one of the key issues that limit fuel cell durability. Carbon has been the preferred support throughout electrocatalysis as a result of the stability, durability, conductivity, and reactivity of the metal/carbon interface. More recent efforts have demonstrated that the introduction of titania can help to stabilize the metal/support interactions at the cathode for oxygen reduction.

Despite the advances in both catalysis and electrocatalysis towards stabilizing the metal/support interface, it is clear that this is an important area which will require mechanistic insights into the fundamental processes that lead to dissolution and loss of metal and practical advances to solve the issues of durability.

\subsection{Oxidation of $\mathrm{CO}$}

3.2.1. Catalytic Oxidation of CO. A second example in which heterogeneous catalysis and electrocatalysis are related is the recent discoveries concerning the unique catalytic activity of supported metal particles in the presence of an aqueous medium. Perhaps most evident is the work that has been carried out over supported Au. Up until 1987, gold was considered to be inert and inactive for catalysis. In a pioneering discovery, Haruta et al. [64, 65] demonstrated that nanometer-sized $\mathrm{Au}$ particles supported on $\mathrm{TiO}_{2}$ were highly active for low-temperature $\mathrm{CO}$ oxidation in the gas phase. This work led to a tremendous number of follow-up studies aimed at understanding the mechanism by which this reaction proceeds and demonstrates the unique behavior of nanometer and subnanometer-sized Au particles in catalyzing a range of different reactions over $\mathrm{TiO}_{2}$ as well as other supports $[66,67]$. A number of possible explanations for the unique reactivity of $\mathrm{Au}$ have been presented in the literature [67] including quantum-size effects [68], increased coordinatively unsaturated edge and corner sites [69], the presence of cationic or anionic $\mathrm{Au}$ centers [70, 71], and unique sites at the $\mathrm{Au} / \mathrm{TiO}_{2}$ interface [72]. While the mechanism is still openly debated, much of the literature suggests that sites along the interface are responsible for the high 
catalytic activity. Some have speculated that the Au-Ti site pairs that result at the $\mathrm{Au} / \mathrm{TiO}_{2}$ interface stabilize the adsorption and activation of $\mathrm{O}_{2}$ or the formation of hydroxyl intermediates both of which can catalyze these reactions [67]. The later idea is supported by the fact that the introduction of small amounts of water or base significantly promotes $\mathrm{CO}$ oxidation over $\mathrm{Au} / \mathrm{TiO}_{2}[73,74]$. Catalysis on these active 2-4 nm-sized Au clusters is thought to be quite different than that found in the electrocatalysis, as the former is carried out in the gas phase at low temperatures over small Au clusters without an applied potential or the presence of promoters. In addition, $\mathrm{O}_{2}$ is the active oxidant in gas phase heterogeneous catalysis, whereas activated water or hydroxyl intermediates are thought to oxidize $\mathrm{CO}$ in electrocatalysis.

Kim et al. [75] and Sanchez-Castillo et al. [76] and Ketchie et al. $[77,78]$ later demonstrated that bulk Au as well as $\mathrm{Au}$ nanotubes were also very active in catalyzing $\mathrm{CO}$ oxidation if the reactions were carried out in an aqueous media. The rates over bulk Au were found to be over an order of magnitude higher in water than those in gas phase. While $\mathrm{CO}$ oxidation can proceed readily in the gas phase for nanometer clusters of $\mathrm{Au}$ on $\mathrm{TiO}_{2}$, water is necessary for carrying the reactions out over bulk $\mathrm{Au}$ as well as $\mathrm{Au}$ supported on carbon.

These same aqueous phase $\mathrm{CO}$ oxidation rates were increased by up to 50 times upon increasing the $\mathrm{pH}$ of solution from neutral conditions $(\mathrm{pH}=7)$ to basic conditions $(\mathrm{pH}=$ 14) and by over an order of magnitude from those in neutral solutions when the reactions were carried out in the presence of $0.5 \% \mathrm{H}_{2} \mathrm{O}_{2}$ [76].

Dumesic et al. suggested that mechanism for CO oxidation in water may proceed via the formation of surface hydroxyl intermediates that can catalyze CO oxidation similar to the classic bifunctional mechanism suggested in electrocatalysis [79-82] and shown previously from theoretical calculations by Desai and Neurock $[83,84]$. In this mechanism, water is activated on Ru sites within a PtRu surface alloy, whereas CO binds/blocks the Pt sites as is shown in Figure 2. CO oxidation proceeds via a nucleophilic attack of the $\mathrm{OH}$ (bound to $\mathrm{Ru}$ ) on a neighboring $\mathrm{CO}$ (bound to $\mathrm{Pt}$ ) coupled with the heterolytic splitting of $\mathrm{O}-\mathrm{H}$ to form $\mathrm{CO}_{2}$ as well as an electron and a proton. This mechanism would also help to explain the significant promotional effects that occur when the reaction is carried out in the presence of base both catalytically $[76,78]$ as well as electrocatalytically $[85,86]$.

3.2.2. Electrocatalytic Oxidation of $C O$ over $A u$. The anodic oxidation of CO over Au/C was actually established in 1965, over two decades before the pioneering work of Haruta $[87,88]$. The reaction readily proceeds over single crystal as well as polycrystalline Au electrodes at low temperature in alkaline media at potentials which are $0.5 \mathrm{~V}$ lower than those found with Pt which is used in most fuel cells. While $\mathrm{CO}$ oxidation readily occurs over single-crystal electrodes in acidic media, the rate is significantly enhanced when carried out in alkaline media. $\mathrm{CO}$ oxidation proceeds over $\mathrm{Au}(111)$ and $\mathrm{Au}(110)$ at potentials of 0.1 and $0.2 \mathrm{~V}$ RHE, respectively, which is $0.5 \mathrm{~V}$ lower than those recorded in acid media [88]. Similar differences for CO oxidation in acidic and alkaline

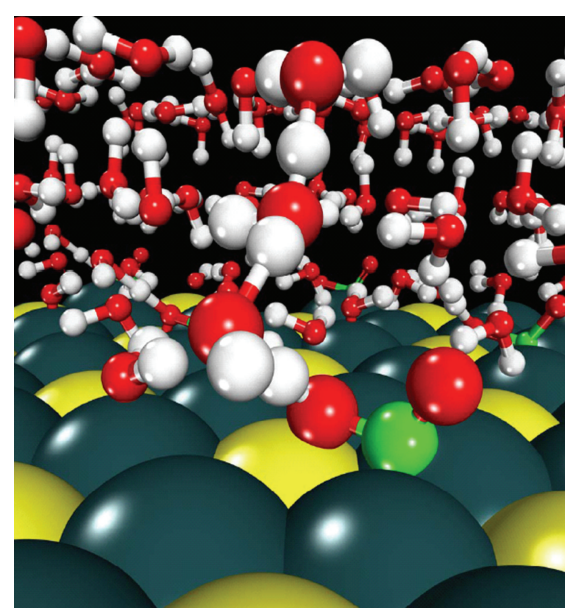

FIGURE 2: DFT-calculated transition state for the electrocatalytic oxidation of CO on Pt (green spheres) by hydroxyls formed via the dissociation of water over $\mathrm{Ru}$ (yellow spheres). The resulting electron is transferred to the metal whereas the proton shuttles away from the surface via the water network (copyright Science [83]).

media also exist for polycrystalline Au. The reaction is thought to proceed via the coupling of $\mathrm{CO}^{*}$ and $\mathrm{OH}^{*}$ in a mechanism that is similar to that presented above in Figure 2. While the reaction proceeds in acidic media, the activation of water to form $\mathrm{OH}^{*}$ on $\mathrm{Au}$ at lower potentials is difficult. The reaction is significantly faster in alkaline media as a result of increased formation of $\mathrm{OH}^{*}$ at lower potentials and the stronger adsorption of $\mathrm{CO}$ at these lower potentials. The higher coverages of $\mathrm{CO}^{*}$ and $\mathrm{OH}^{*}$ in alkaline media further enhance the rate of reaction at the lower potentials. This shift in potential results in an increase in electron density at the metal surface which further enhances backdonation. Rodriguez et al. $[88,89]$ suggested that the increased $\mathrm{CO}$ adsorption further enhances the adsorption of $\mathrm{OH}$ and selfpromotes the reaction.

Nearly all of the early electrocatalytic studies were carried out over bulk polycrystalline Au electrodes. The exceptional findings by Haruta et al. [64, 65] and the suggestions of the unique interface for nanoparticles of Au supported on $\mathrm{TiO}_{2}$ prompted Hayden et al. $[85,86]$ to examine the electrocatalytic oxidation of $\mathrm{CO}$ over nanoparticles of $\mathrm{Au}$ on $\mathrm{TiO}_{2}$. They demonstrated considerable enhancements in the electrocatalytic rates of $\mathrm{CO}$ oxidation for $\mathrm{Au}$ nanoparticles supported on $\mathrm{TiO}_{2}$ even when the reaction is carried out in acidic media. The enhancement was attributed to the substrate-induced reactivity of $\mathrm{Au}$ as discussed below [85, 86].

3.2.3. Particle Size Effects on CO Oxidation. The results from gas phase catalysis carried out over supported Au clusters indicate that the reaction is structure sensitive where the highest catalytic activity occurs for $2-4 \mathrm{~nm}$ sized particles supported on $\mathrm{TiO}_{2}[66,67]$. The results in aqueous media, however, are not as clear. Ketchie et al. show a significant increase in the activity in moving from $42 \mathrm{~nm}$ down to $5 \mathrm{~nm}$ [77]. The activity on 2-3 nm-sized clusters, however, was 
more difficult to quantify as a result of difficulties in the synthesis of monodisperse particles $[64,65,67]$. Under electrochemical conditions, Hayden et al. $[85,86]$ showed that while polycrystalline Au electrodes readily oxidize $\mathrm{CO}$ to $\mathrm{CO}_{2}$, they require overpotentials greater than $0.7 \mathrm{~V}$ as $\mathrm{AuO}$ forms and inhibits the reaction. They demonstrated significant structure sensitivity in the reaction, whereby $3 \mathrm{~nm}$ $\mathrm{Au}$ particles were much more active even at potentials as low as $0.3 \mathrm{~V}$. Au particles smaller than $2.5 \mathrm{~nm}$ showed a significant decrease in activity as did particles larger than $3.5 \mathrm{~nm}$. They speculate that the loss in activity below $3 \mathrm{~nm}$ is the result of quantum size effects rather than from irreversibly adsorbed oxygen. There appears to be clear similarities for particle size effects in comparing the results for $\mathrm{CO}$ oxidation under electrocatalytic conditions with those found for $\mathrm{Au} / \mathrm{TiO}_{2}$ in the gas phase heterogeneous catalysis. The reactions over $\mathrm{Au} / \mathrm{C}$ in solution, however, were less conclusive.

3.2.4. CO Oxidation Mechanisms. As was suggested earlier, the heterogeneous catalytic and the electrocatalytic oxidation of CO may proceed by common mechanisms or at least common features in the mechanism. We compare the mechanistic ideas for the catalytic and electrocatalytic oxidation of $\mathrm{CO}$ over both $\mathrm{TiO}_{2}$ and carbon supports.

(1) Catalytic and Electrocatalytic Oxidation of $\mathrm{CO}$ over $\mathrm{TiO}_{2}$. The unique reactivity of nanometer-sized $\mathrm{Au}$ particles on $\mathrm{TiO}_{2}$ used in both catalysis as well as electrocatalysis is thought to be dictated by sites at the $\mathrm{Au} / \mathrm{TiO}_{2}$ interface. We have recently shown that the Ti cations in direct proximity to the adsorbed Au become positively charged as a result of local charge transfer from $\mathrm{Au}$ to local $\mathrm{Ti}^{5+}$ cations as is shown in Figure 3 [90]. This increase in charge along with the direct involvement of both $\mathrm{Au}$ and $\mathrm{Ti}^{5+}$ atoms stabilize the bidentate adsorption of $\mathrm{O}_{2}$. This increases the $\mathrm{O}_{2}$ adsorption strength by nearly $60 \mathrm{~kJ} / \mathrm{mol}$ and promotes its activation at these dual interface sites. This subsequently catalyzes the reaction between $\mathrm{O}_{2}$ coadsorbed CO. While $\mathrm{O}_{2}$ is not present in the electrocatalytic oxidation of $\mathrm{CO}$, water can adsorb and activate at these same perimeter sites. DFT calculations indicate that the adsorption of water at this same charged interfacial $\mathrm{Ti}^{5+}$ site is $-104 \mathrm{~kJ} / \mathrm{mol}$, whereas water on $\mathrm{a} \mathrm{Ti}^{5+}$ site removed from $\mathrm{Au}$ and on a $\mathrm{Au}$ site near the support are significantly weaker at $-77 \mathrm{~kJ} / \mathrm{mol}$ and $-8 \mathrm{~kJ} / \mathrm{mol}$, respectively. These Au-Ti perimeter sites likely attenuate the activation of water. The resulting intermediate (either activated water or surface hydroxyl groups) can then react with coadsorbed $\mathrm{CO}$ to form $\mathrm{CO}_{2}$. This is consistent with the results from Hayden et al. $[85,86]$ who showed a direct relationship between electrocatalytic activity and the perimeter of the particle and was able to rule out the influence of low coordinate $\mathrm{Au}$ atoms and quantum size effects.

The differences between the gas phase reactions and the electrocatalytic reactions may simply be the nature of the active oxidant that forms. In the presence of water, the oxidant involved in catalysis and electrocatalysis is likely the same.

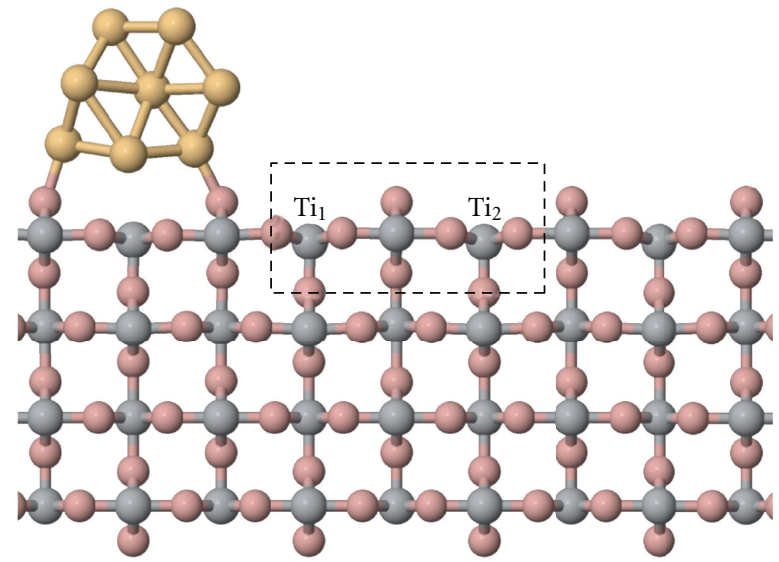

(a)

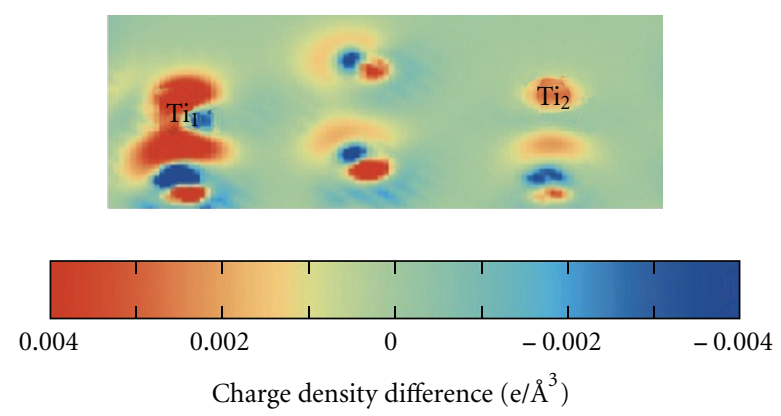

(b)

FIgURE 3: Charge density difference that results at $\mathrm{Ti}^{5+}$ centers of $\mathrm{TiO}_{2}$ adjacent to $\mathrm{Au}$ upon the adsorption of $\mathrm{Au}$ nanorods or clusters. (Copyright Science [90]).

(2) Au/C The Effects of Water and Base. The heterogeneous oxidation of $\mathrm{CO}$ over bulk $\mathrm{Au} / \mathrm{C}$ in water appears to proceed via a mechanism that involves the nucleophilic addition of $\mathrm{OH}$ groups present in solution or on the surface formed under reaction conditions to adsorbed CO*. This results in the formation of $\mathrm{CO}_{2}$ and either adsorbed hydrogen or a proton and an electron.

$$
\begin{aligned}
& \mathrm{CO}^{*}+\mathrm{OH}^{*} \longrightarrow \mathrm{COOH}^{*} \longrightarrow \mathrm{CO}_{2}(\mathrm{aq})+\mathrm{H}^{*}+{ }^{*} \\
& \mathrm{CO}^{*}+\mathrm{OH}^{*} \longrightarrow \mathrm{COOH}^{*} \longrightarrow \mathrm{CO}_{2}(\mathrm{aq})+\mathrm{H}^{+}+\mathrm{e}^{-}+*
\end{aligned}
$$

The latter is identical to the mechanism typically proposed in electrocatalysis. The results for the heterogeneous CO oxidation in water over $\mathrm{Au} / \mathrm{C}$ indicate that the reaction can proceed solely by the presence of $\mathrm{H}_{2} \mathrm{O}_{2}$ and water without oxygen [76]. In the presence of oxygen, small amounts of $\mathrm{H}_{2}$ are formed possibly as the result of the water gas shift reaction [76]. Both of these results strongly suggest that $\mathrm{OH}$ groups are formed and directly participate in the oxidation mechanism [76]. Similar reactions occur in the electrocatalytic oxidation of $\mathrm{CO}$ over $\mathrm{Au} / \mathrm{C}$ in both acid as well as alkaline media. 


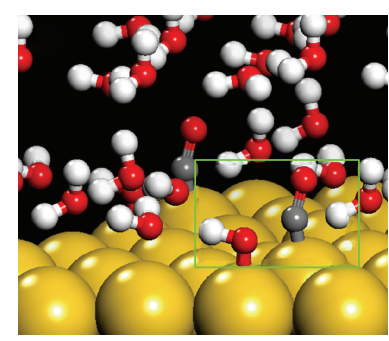

(a)

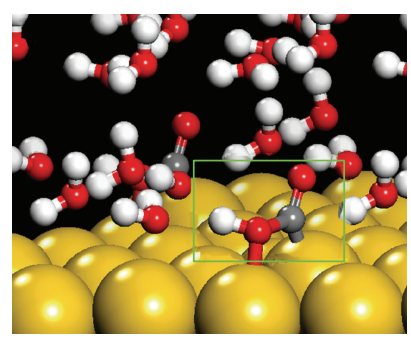

(b)

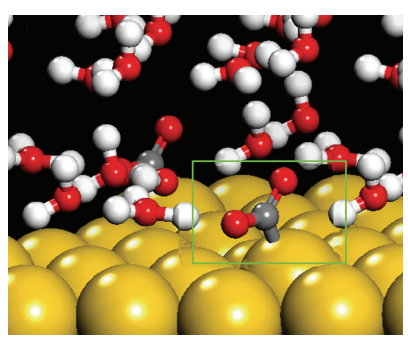

(c)

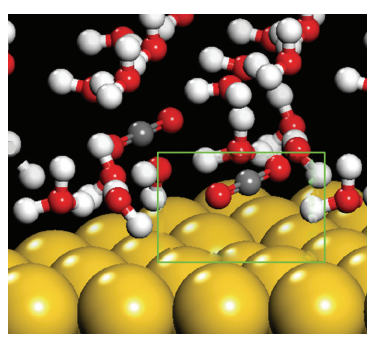

(d)

FIGURE 4: DFT-calculated reaction coordinate for the oxidation of $\mathrm{CO}$ via adsorbed $\mathrm{OH}^{*}$ over Au. The reaction proceeds via: (a) the coadsorption of $\mathrm{CO}^{*}$ and $\mathrm{OH}^{*}$, (b) the nucleophilic attack of $\mathrm{OH}^{*}$ on $\mathrm{CO}^{*}$ to form the $\mathrm{HO}^{*}{ }^{*} \mathrm{CO}$ surface intermediate, (c) cleavage of $\mathrm{O}-\mathrm{H}$ bond in the transition state, and (d) formation of $\mathrm{CO}_{2}$ and $\mathrm{H}_{3} \mathrm{O}^{+}$products. The active $\mathrm{CO}^{*}$ and $\mathrm{OH}^{*}$ surface species are highlighted in green as they proceed through the reaction.

In order to model the oxidation of $\mathrm{CO}$ over bulk $\mathrm{Au}$ in solution, we have carried out detailed density functional theory calculations with $\mathrm{CO}$ and $\mathrm{OH}$ or $\mathrm{H}_{2} \mathrm{O}$ adsorbed on a $\mathrm{Au}(111)$ surface immersed in water [91]. The resulting activation barrier for the reaction (2) above was calculated to be negligible, whereas the overall reaction energy was calculated to be exothermic by $-231 \mathrm{~kJ} / \mathrm{mol}$. Various structures along the reaction coordinate are shown in Figure 4. The reaction proceeds via the formation of the $\mathrm{OC}-\mathrm{OH}$ bond combined with the heterolytic splitting of the $\mathrm{O}-\mathrm{H}$ bond to form an $\mathrm{H}_{3} \mathrm{O}^{+}$intermediate which subsequently undergoes a second proton transfer to another water molecule.

The overall mechanism for the heterogeneous catalyzed oxidation of CO may proceed via the formation of local electrochemical cell or circuit, where $\mathrm{CO}$ is oxidized by $\mathrm{OH}$ resulting in the formation of proton and an electron which subsequently catalyzes the reduction of $\mathrm{O}_{2}$ to the active $\mathrm{OH}$ intermediates or to $\mathrm{H}_{2} \mathrm{O}_{2}$. This is discussed in somewhat more detail in Section 3.3.2(1). These same ideas on the oxidation of $\mathrm{CO}$ can readily be extended to methanol as well as other alcohols.

3.3. Alcohol Oxidation. The increasing demand to shift from petroleum-based fuels and chemical to those derived from biomass has significantly increased efforts in both the electrocatalytic and catalytic oxidation of carbohydrates feedstocks. Significant efforts have been focused on the selective oxidation of methanol, ethanol, glycerol, and other $\mathrm{C}_{2}-\mathrm{C}_{6}$ polyols into chemical intermediates via heterogeneous catalysis [92-98] as well as the total oxidation of these fuels to electrical energy via electrocatalysis [99-107]. In the next few sections, we compare some of the similarities and differences involved in the catalytic and electrocatalytic oxidation of these alcohols in acidic as well as alkaline media.

\subsubsection{Alcohol Oxidation in Acidic Media}

(1) Catalytic. The catalytic oxidation of glycerol as well as ethanol is rather low when carried out in neutral solution over Pd and Pt with reported turnover frequencies of 0.05 and $0.06 \mathrm{~s}^{-1}$, respectively [98]. The products that form over these metals are predominantly intermediate aldehydes and ketones that result from dehydrogenation with only $25 \%$ selectivity to form the acid product. Glycerol oxidation, for example, leads to the formation of glyceraldehyde as well as dihydroxyacetone without further oxidation to $C_{1}$ or $C_{2}$ acids or $\mathrm{CO}_{2}$. Supported Au clusters under neutral and acidic conditions were found to be completely inactive [98].

The dehydrogenation reactivity that results over Pd and $\mathrm{Pt}$ can proceed via $\mathrm{C}-\mathrm{H}$ and $\mathrm{O}-\mathrm{H}$ activation over the metal or by adsorbed oxygen or hydroxyl intermediates that form upon $\mathrm{O}_{2}$ dissociation or by the subsequent reaction of adsorbed oxygen with water. DFT-calculated activation barriers suggest that $\mathrm{O}-\mathrm{H}$ activation of ethanol occurs via the reaction of adsorbed ethanol with $\mathrm{OH}^{*}$, whereas the C$\mathrm{H}$ activation of ethanol preferentially occurs via metal sites on the Pt and Pd surfaces [98]. Both reactions, however, are limited on Pt and Pd, as the high surface coverages on these metals result in barriers for both $\mathrm{C}-\mathrm{H}$ and $\mathrm{O}-\mathrm{O}$ activation that are significantly greater than $100 \mathrm{~kJ} / \mathrm{mol}$. The oxidation of alcohols over Au does not proceed over $\mathrm{Au}$ alone under neutral or acidic conditions as gold cannot activate water, $\mathrm{O}_{2}$, or alcohol [98].

(2) Electrocatalytic. The oxidation of methanol, ethanol, glycerol, and other alcohols occurs in acidic media but requires significantly higher overpotentials than reactions carried out in alkaline media $[79,100,108-119]$. The oxidation of methanol proceeds over most transition metals through a sequence of elementary $\mathrm{C}-\mathrm{H}$ and $\mathrm{O}-\mathrm{H}$ bond activation steps which occur on the metal, and ultimately result in the formation of CO $[79,109,110]$. Through the combination of cyclic voltammetry, chronoamperometry, and DFT studies, we demonstrated that the methanol decomposition occurs via a dual path mechanism $[1,120]$. At potentials below $0.35 \mathrm{~V}$, the mechanism proceeds predominantly through a sequence of $\mathrm{C}-\mathrm{H}$ activation steps to form the hydroxyl methylene $\left(\mathrm{CHOH}^{*}\right)$ intermediate that subsequent breaks the $\mathrm{O}-\mathrm{H}$ and $\mathrm{C}-\mathrm{H}$ bonds to form $\mathrm{CO}^{*}$. At potentials above $0.35 \mathrm{~V}$, the $\mathrm{O}-$ $\mathrm{H}$ bond of methanol can also be activated, resulting in the formation of formaldehyde which can desorb or continue on to form CO. The onset potential was found to be a function of the Pt surface structure. The dual paths for the oxidation of methanol to $\mathrm{CO}$ over $\mathrm{Pt}(111)$ along with their 


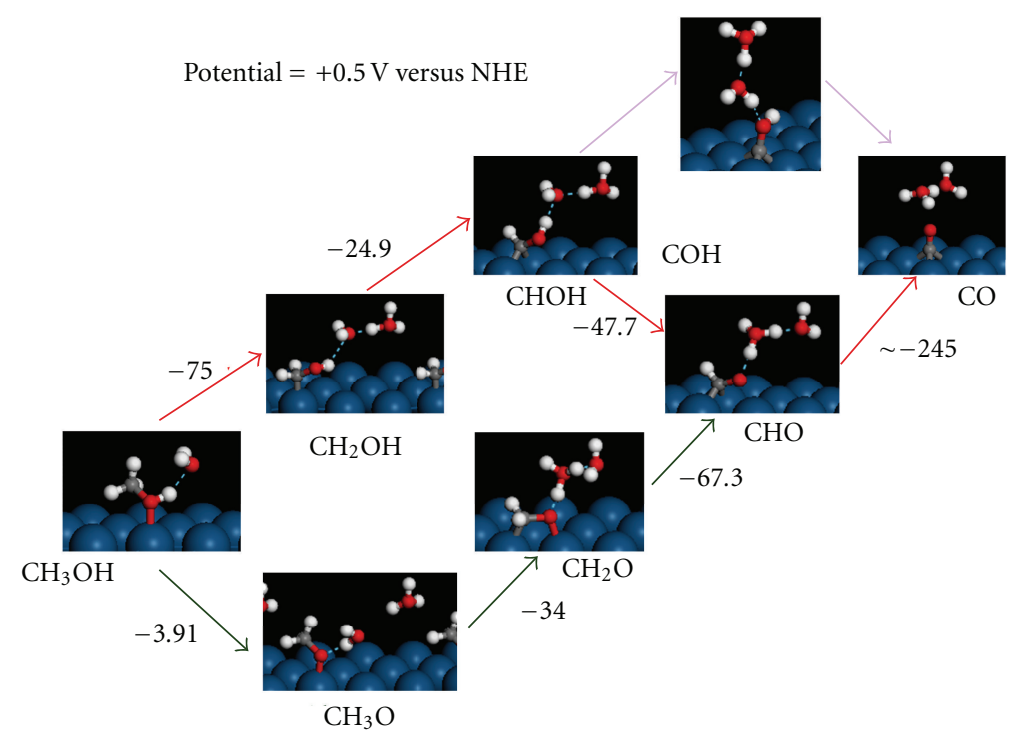

FIGURE 5: DFT-calculated potential-dependent reaction paths for the oxidation of methanol to CO over Pt(111) [1]. At 0.5 V, both experiments and theory point to the onset of dual paths. The primary path, available over a wide range potentials, is shown in red. It proceeds via a sequence of $\mathrm{C}-\mathrm{H}$ bond activation steps ultimately forming the hydroxyl methylene intermediate $(\mathrm{CHOH})$ before activating the final $\mathrm{O}-\mathrm{H}$ bond to form $\mathrm{CO}$. The minor path begins between $0.4-0.5 \mathrm{~V}$ RHE proceeds via the initial activation of $\mathrm{O}-\mathrm{H}$ bond of methanol to form a surface methoxy intermediate which subsequently reacts to form formaldehyde consistent with previous speculations [122].

corresponding reaction energies calculated at $0.5 \mathrm{~V}$ RHE are shown in Figure $5[1,120]$. While $\mathrm{CO}$ is an intermediate to $\mathrm{CO}_{2}$, it readily builds up on the surface and poisons more active metals such as Pt. As such, Pt is typically alloyed with a more oxophilic metal such as Ru to promote the adsorption and dissociation of water thus creating bifunctional sites on the surface $[79,109,110]$. The $\mathrm{OH}$ groups that result interrupt the $\mathrm{CO}$ adlayer and readily oxidize $\mathrm{CO}$ to $\mathrm{CO}_{2}$. The addition of $\mathrm{Ru}$ also helps to weaken the $\mathrm{Pt}-\mathrm{CO}$ bond thus enhancing $\mathrm{CO}$ desorption. The addition of $\mathrm{Ru}$ to Pt lowers the overpotential for $\mathrm{CO}$ oxidation by $\sim 0.25 \mathrm{~V}[80-82,121]$ as it prevents $\mathrm{CO}$ poisoning.

The oxidation of ethanol, glycerol and other larger alcohols in acidic media result in dehydrogenation which forms the corresponding aldehyde [114-117]. The subsequent activation of the $\mathrm{C}-\mathrm{C}$ bond, however, is very difficult over typical metals such as $\mathrm{Pt}, \mathrm{Pd}$, or $\mathrm{Au}$, and as such, very limited $\mathrm{CO}_{2}$ is formed. The dehydrogenation routes are identical to those presented above for the catalytic oxidation of the same alcohols. The higher potentials used electrochemically can activate water at higher potentials, and thus result in the formation of surface hydroxyl intermediates that can subsequently oxidize the aldehyde and ketone intermediates [115]. This leads to the formation of acids as well as carboxylate intermediates which inhibit the surface under acidic conditions and prevent the formation of $\mathrm{CH}_{\mathrm{x}}$ intermediates on closed-packed crystal surfaces. Feliu et al. have shown that steps on specific $\mathrm{Pt}$ surfaces $\mathrm{Pt}(554)$ and $\mathrm{Pt}(110)$ can begin to enhance $\mathrm{C}-\mathrm{C}$ bond breaking and $\mathrm{CO}_{2}$ formation, but rate is still very limited $[111,114]$.

The electrooxidation of ethanol over Pt in acidic media has two major limitations which prevent its viability as was discussed by Lia et al. [115]. The first relates to the fact that reaction predominantly produces acetate and acetic acid intermediates, thus resulting in only 2 and 4 electrons, respectively, which are only very minor contributions to total possible current. Both are thus unwanted side products for fuel cell applications. The second limitation is that the path to $\mathrm{CO}_{2}$ is rather difficult in that it requires the activation of $\mathrm{C}-\mathrm{C}$ bond as well as the oxidation of both the $\mathrm{CH}_{\mathrm{x}}$ and $\mathrm{CO}$ intermediates that form. Both of these intermediates tend to inhibit or poison metal surfaces at lower potentials [48].

The characteristic difference between the catalytic oxidation and electrocatalytic oxidation of alcohols in acidic media lies in the generation of the active surface intermediate. In heterogeneous catalysis, the metal plays an important role in activating oxygen. The surface oxygen can directly activate the alcohol or adsorbed water to generate hydroxyl intermediates that aid in activating and oxidizing the alcohol. Under electrocatalytic conditions, the $\mathrm{O}-\mathrm{H}$ and $\mathrm{C}-\mathrm{H}$ bonds of the alcohol can be activated on the metal directly as a result of higher potentials or via adsorbed hydroxyl intermediates that form by the activation of water.

\subsubsection{Alcohol Oxidation in Alkaline Media}

(1) Catalytic. The catalytic oxidation of polyols over Pd, Pt, and $\mathrm{Au}$ is much more favorable when carried out in alkaline media $[78,98,123]$. The TOF increases by over an order of magnitude on Pt and over two orders of magnitude on $\mathrm{Pd}$ upon the addition of a 2/1 ratio of $\mathrm{NaOH}$ to glycerol [98]. Remarkably, the TOF over gold in base is over $6 \mathrm{~s}^{-1}$, whereas the rate over Au in acidic media is negligible [98]. In addition to these increases in TOF, there are also significant 


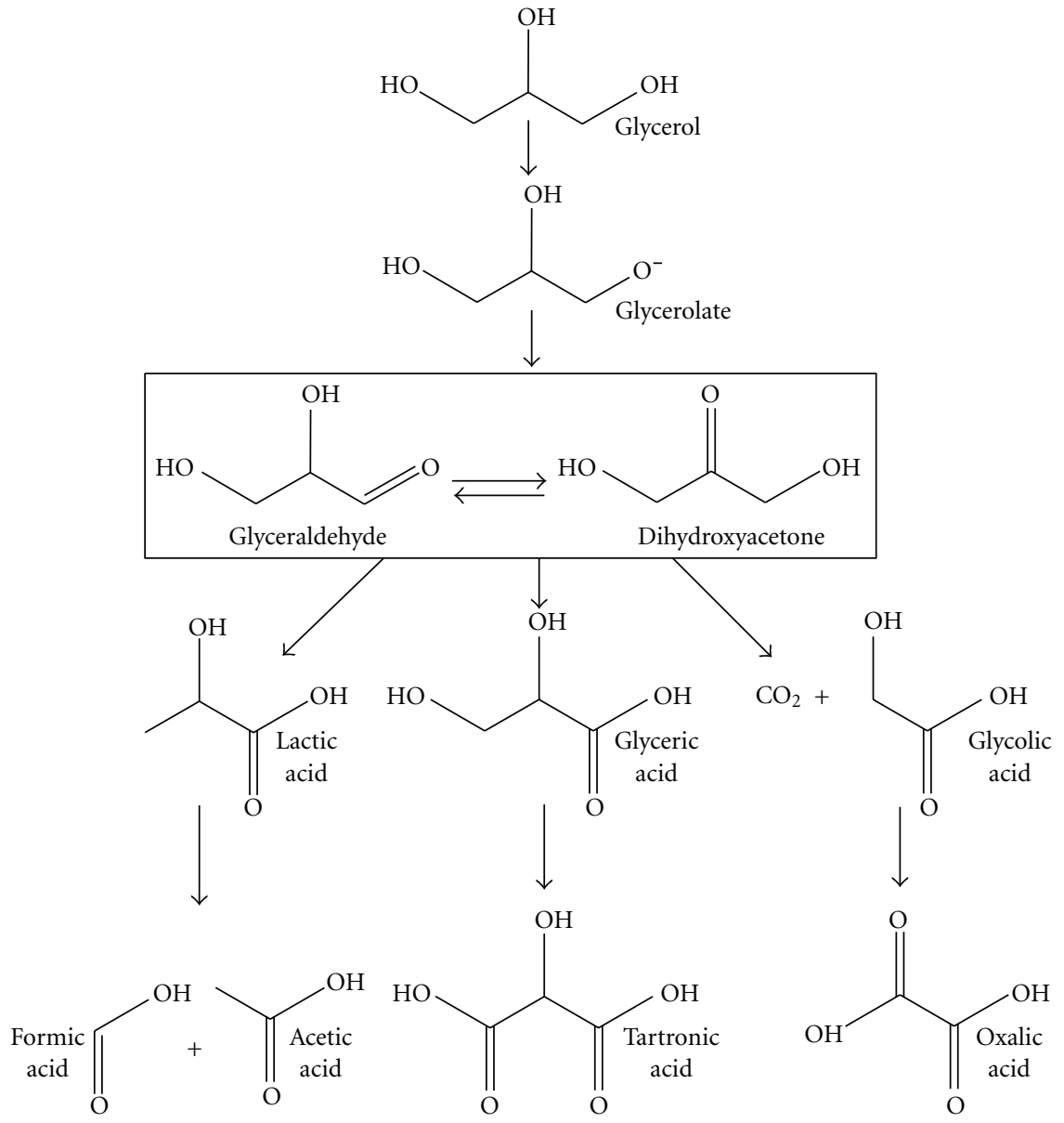

Figure 6: Reaction pathways speculated in the catalytic and electrocatalytic oxidation of glycerol over Au and Pt. Arrows in red depict paths observed over Au and Pt whereas the paths in black are only observed over Pt. Adapted from [123].

improvements in the overall selectivity to form the acid from the alcohol. For glycerol, the selectivity to glyceric acid was found to be $83 \%$ over Pd, $70 \%-78 \%$ over $\mathrm{Pt}$, and $67 \%$ over $\mathrm{Au}$ [98]. The predominant side products are glycolic and tartronic acid which are shown in the paths outlined in Figure 6 . In the presence of base, the second terminal hydroxyl group can be oxidized to form tartronic acid, but this only occurs over $\mathrm{Pt}$ and $\mathrm{Pd}$. The oxidation over $\mathrm{Au}$ results only in the monofunctional glyceric acid product. In addition to the selective oxygen addition, $\mathrm{Pd}$ and $\mathrm{Pt}$ can also promote $\mathrm{C}-\mathrm{C}$ activation resulting in the formation of glycolic, oxalic, lactic, formic, and acetic acids. These $\mathrm{C}-\mathrm{C}$ activation paths appear to coincide with the formation of hydrogen peroxide [123]. The activation of the $\mathrm{C}-\mathrm{C}$ bonds have been speculated to occur either through a retroaldol reaction which would be catalyzed by the $\mathrm{OH}^{-}$base, or via oxidation catalyzed by the hydrogen peroxide that forms [78, 123].

Through detailed labeling studies along with DFT simulations, we established a plausible mechanism for the oxidation of alcohols over Au in basic media [98]. The mechanism also helps to explain the unique promotional effects of $\mathrm{OH}$ on $\mathrm{Au}$. We discuss here the energetics involved in the reaction over the model $\mathrm{Au}(111)$ surface. The first step involves the dehydrogenation of the alcohol to form the corresponding aldehyde. This can proceed via the activation of the $\mathrm{O}-$ $\mathrm{H}$ and $\mathrm{C}-\mathrm{H}$ bonds of the alcohol by the metal, adsorbed oxygen, or adsorbed $\mathrm{OH}$ intermediates. As one might expect, $\mathrm{Au}$ atoms alone cannot activate the $\mathrm{O}-\mathrm{H}$ bond of the alcohol. The calculated barrier to activate ethanol to ethoxy over $\mathrm{Au}(111)$ in the presence of solution was calculated to be $204 \mathrm{~kJ} / \mathrm{mol}$ (the transition state is shown in Figure 7(a)). The $\mathrm{O}-\mathrm{H}$ bonds are much more readily activated by the weakly adsorbed $\mathrm{OH}^{\delta-}$ intermediates via a mechanism which involves a proton abstraction by the $\mathrm{OH}^{\delta-}$ surface intermediate (the transition state is shown in Figure 7(b)). The inability of $\mathrm{Au}(111)$ to activate the $\mathrm{O}-\mathrm{H}$ and $\mathrm{C}-\mathrm{H}$ bonds is well established, as bulk $\mathrm{Au}$ is quite noble. The binding energy of $\mathrm{OH}^{* \delta-}$ on $\mathrm{Au}(111)$ in water is only $-216 \mathrm{~kJ} / \mathrm{mol}$ (versus $-274 \mathrm{~kJ} / \mathrm{mol}$ on $\operatorname{Pt}(111)$ ), thus making it quite basic. The weak interaction promotes its ability to readily abstract a proton from a neighboring $\mathrm{O}-\mathrm{H}$ on the alcohol. Similarly, the activation of the $\mathrm{C}-\mathrm{H}$ bond of the ethoxy intermediate to form acetaldehyde does not occur over $\mathrm{Au}(111)$ alone (see the transition state in Figure 7(c)) but instead proceeds by the reaction of $\mathrm{OH}^{* \delta-}$ with the adsorbed ethoxy intermediate with a barrier of only $12 \mathrm{~kJ} / \mathrm{mol}$ (see the transition state in 


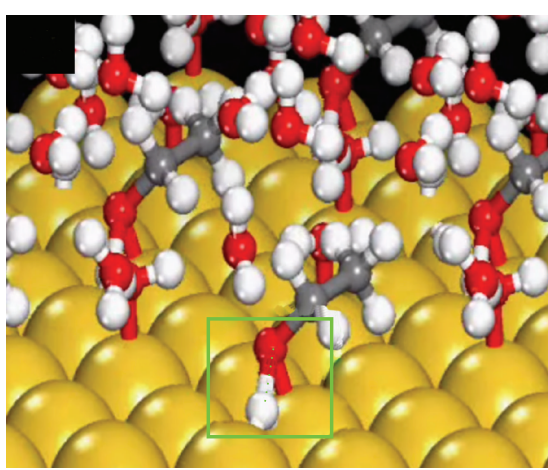

(a)

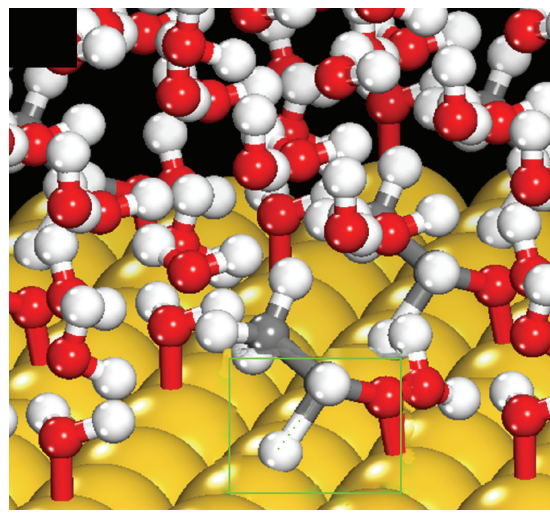

(c)

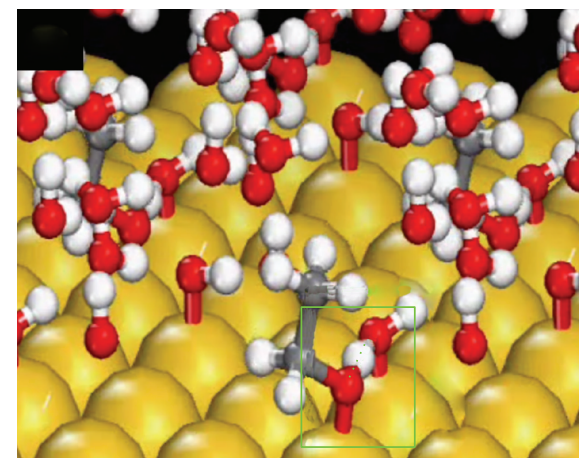

(b)

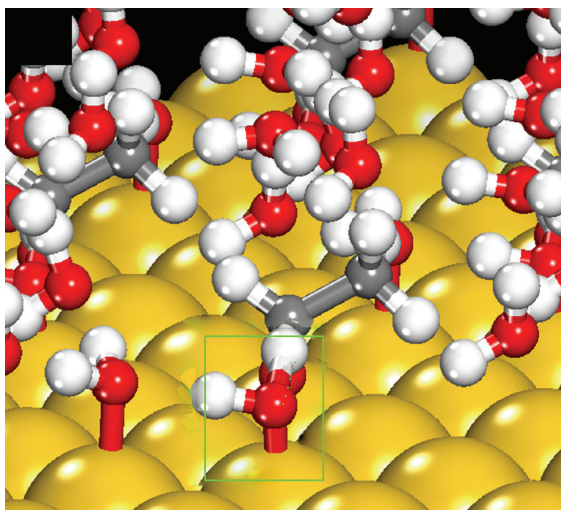

(d)

Figure 7: DFT-calculated transition states for the activation of the $\mathrm{O}-\mathrm{H}$ bond of ethanol adsorbed to Au by (a) metal surface atom or (b) a coadsorbed hydroxyl intermediate on $\mathrm{Au}(111)$. The activation of the $\mathrm{C}-\mathrm{H}$ bonds of the adsorbed ethoxy are activated similarly via (c) $\mathrm{Au}$ atoms in the $\mathrm{Au}(111)$ surface or (b) via the bound $\mathrm{OH}$ groups on the $\mathrm{Au}(111)$ surface. The active bond breaking and forming sites are highlighted in green.

Figure $7(\mathrm{~d})$ ). The aldehyde that results is a key reaction intermediate to form the acid in alkaline media over Au.

Most of the initial studies in the aqueous phase catalytic oxidation of alcohols assumed that $\mathrm{O}_{2}$ was responsible for carrying out the oxidation. By carrying out the reaction with ${ }^{18} \mathrm{O}$-labeled $\mathrm{O}_{2}$ and $\mathrm{H}_{2} \mathrm{O}$, however, we showed that only labeled water found its way into the resulting acid product that forms [98]. DFT results for $\mathrm{Au}$ in an aqueous medium showed that this reaction proceeds via a classic nucleophilic attack of $\mathrm{OH}^{* \delta-}$ on the adsorbed aldehyde quite similar to thought found for the oxidation of CO. The barrier to form the geminal diol intermediate shown in Figure 8(a) was only $5 \mathrm{~kJ} / \mathrm{mol}$ when carried out over Au and $42 \mathrm{~kJ} / \mathrm{mol}$ for reactions in the solution phase Figure 8(b). The final $\mathrm{C}-\mathrm{H}$ activation of the germinal diol to form the acid can proceed over the Au itself $(21 \mathrm{~kJ} / \mathrm{mol})$ or via reaction with adsorbed $\mathrm{OH}^{* \delta-}(29 \mathrm{~kJ} / \mathrm{mol})$. A schematic representation of the mechanism which involves the unique reactivity of $\mathrm{OH}^{-}$ intermediates at the aqueous/Au interface for the selective oxidation of the alcohol to the acid is depicted in Figure 9, whereas the corresponding potential energy surface is shown in Figure 10. This oxidation path proceeds without the activation or incorporation of oxygen from $\mathrm{O}_{2}$.

While $\mathrm{O}_{2}$ is not directly involved in any of the steps depicted in the mechanism for alcohol oxidation shown in
Figure 10, it is critical as the reaction does not occur without it. Oxygen must somehow be intimately coupled with the overall catalytic process which requires the balance of charge and the regeneration of $\mathrm{OH}^{-}$. As the result of theoretical calculations, we showed that oxygen is necessary to remove the electrons that are generated as result of the oxidation of the alcohol. The measured rate for the oxidation reaction is 6.1 turnovers per second per site [98]. As the steps outlined in the cycle presented in Figure 10 consume 4 hydroxyl ions, they generate 4 electrons per every turnover.

$$
\mathrm{RCH}_{2} \mathrm{OH}+4 \mathrm{OH}^{-} \longrightarrow \mathrm{RCOOH}+3 \mathrm{H}_{2} \mathrm{O}+4 \mathrm{e}^{-}
$$

In order for the reaction to occur catalytically, the electrons that are produced per turnover must be consumed. Each oxygen molecule can effectively remove 4 electrons via the oxygen reduction reaction (ORR).

$$
\mathrm{O}_{2}+2 \mathrm{H}_{2} \mathrm{O}+4 \mathrm{e}^{-} \longrightarrow 4 \mathrm{OH}^{-}
$$

The oxygen reduction reaction is known to occur quite readily over single crystal Au electrodes. DFT calculations were used to determine the reaction energies and the activation barriers for the most relevant steps for ORR. The results reported in Table 1 indicate that the direct dissociation of $\mathrm{O}_{2}$ (reaction 5) does not take place over $\mathrm{Au}$ as is well established 
TABLE 1: DFT-calculated reaction energies and activation barriers for possible steps involved in the reduction of $\mathrm{O}_{2}$ to $\mathrm{OH}$ over $\mathrm{Au}(111)$ in aqueous media [98].

\begin{tabular}{lccc}
\hline & $\Delta E_{\mathrm{rxn}}(\mathrm{kJ} / \mathrm{mol})$ & $\Delta E^{*}(\mathrm{~kJ} / \mathrm{mol})$ & Reaction \\
\hline $\mathrm{O}_{2}{ }^{*}+{ }^{*} \rightarrow \mathrm{O}^{*}+\mathrm{O}^{*}$ & 41 & 105 & $(5)$ \\
$\mathrm{O}_{2}{ }^{*}+\mathrm{H}_{2} \mathrm{O}^{*} \rightarrow \mathrm{OOH}^{*}+\mathrm{OH}^{*}$ & -4 & 16 & $(6)$ \\
$\mathrm{OOH}^{*}+{ }^{*} \rightarrow \mathrm{OH}^{*}+\mathrm{O}^{*}$ & -56 & 83 & $(7)$ \\
$\mathrm{OOH}^{*}+\mathrm{H}_{2} \mathrm{O}^{*} \rightarrow \mathrm{HOOH}^{*}+\mathrm{OH}^{*}$ & 37 & 48 & $(8)$ \\
$\mathrm{HOOH}^{*}+{ }^{*} \rightarrow \mathrm{OH}^{*}+\mathrm{OH}^{*}$ & -86 & 71 & $(9)$ \\
\hline
\end{tabular}

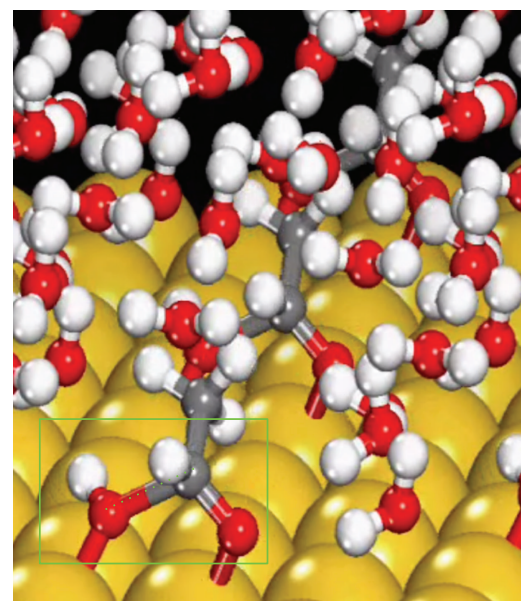

(a)

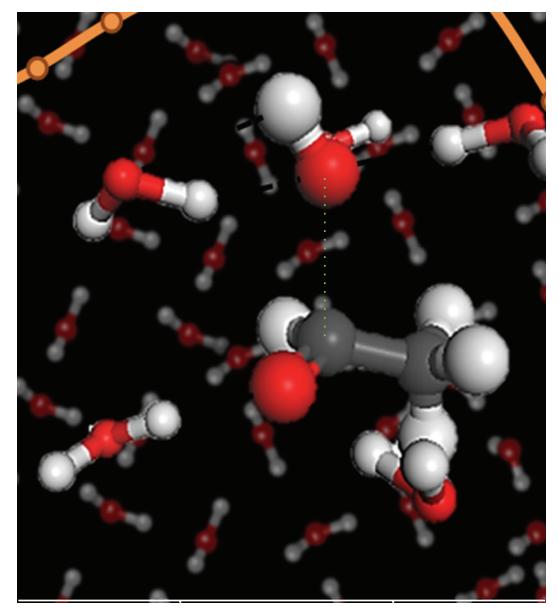

(b)

FIGURE 8: DFT-calculated transition states and their activation barriers for the oxidation of acetaldehyde on (a) the Au(111) surface or (b) in the presence of solution. The active bond breaking and forming sites are highlighted in green.

experimentally. Oxygen instead is reduced by the protons from water and the electrons in the metal to form a peroxo intermediate along with $\mathrm{OH}^{-}$(reaction 6). The peroxo intermediate is subsequently reduced to hydrogen peroxide (reaction 7) which can subsequently dissociate and result in the formation $2 \mathrm{OH}^{-}(\mathrm{aq})$. The intermediate formation of hydrogen peroxide is consistent with observed experimental results and suggestions that peroxide is responsible for $\mathrm{C}-\mathrm{C}$ bond breaking and formation of shorter acids.

This overall ORR cycle removes the 4 electrons from the metal produced via the oxidation, and thus allows the reaction to continue catalytically. The cycle also regenerates $\mathrm{OH}^{-}(\mathrm{aq})$. The overall catalytic reaction then involves the direct coupling of both alcohol oxidation and oxygen reduction cycles in one system. This can thus be considered a local, short-circuited, electrochemical cell, where the oxidation and reduction occur simultaneously at the metal/surface interface. The role of $\mathrm{O}_{2}$ then is to simply to remove the electrons from the metal at a rate fast enough to maintain the optimal surface potential of the local electrochemical cell.

(2) Electrocatalytic. The development and application of carbonate as well as anion-exchange membrane electrolytes have significantly renewed interest in the development of alkaline-based direct alcohol fuel cells [100]. Many of the reaction intermediates, products, and paths discussed above for the catalytic oxidation of alcohols in alkaline media have also been identified or speculated to take part in the electrocatalytic oxidation of these same alcohols. As such, the mechanistic insights established from catalytic oxidation should be important in understanding the chemistry and the mechanisms that control electrocatalytic oxidation. Similarly, the detailed insights established from electrochemical methods such as cyclic voltammetry should provide new insights into heterogeneous catalytic oxidation.

The oxidation of methanol, ethanol, as well as other polyols in alkaline media is thought to proceed either by $4 \mathrm{e}^{-}$ or $6 \mathrm{e}^{-}$processes thus resulting in the formation of either formate and carbonate intermediates by reactions (5), or (6) [100]

$$
\begin{gathered}
\mathrm{RCH}_{2} \mathrm{OH}+5 \mathrm{OH}^{-} \longrightarrow \mathrm{HCOO}^{-}+4 \mathrm{H}_{2} \mathrm{O}+4 \mathrm{e}^{-} \\
\mathrm{RCH}_{2} \mathrm{OH}+8 \mathrm{OH}^{-} \longrightarrow \mathrm{CO}_{3}{ }^{2-}+6 \mathrm{H}_{2} \mathrm{O}+6 \mathrm{e}^{-}
\end{gathered}
$$

For methanol, the later reaction is speculated to occur through the formation of CO. In the presence of base, surface $\mathrm{OH}^{-}$groups readily catalyze the oxidation of methanol to $\mathrm{CO}_{2}$ or carbonate as shown in reactions (5) and (6), respectively. At higher potentials, however, $\mathrm{OH}$ binds very strongly to the metal surface and inhibits the reaction. The selectivity to formate or carbonate depends upon the metal, metal surface structure, potential $\mathrm{pH}$, and alcohol concentration present during the reaction. We discuss here the difference in the electrocatalytic oxidation over Pt and Au and compare 


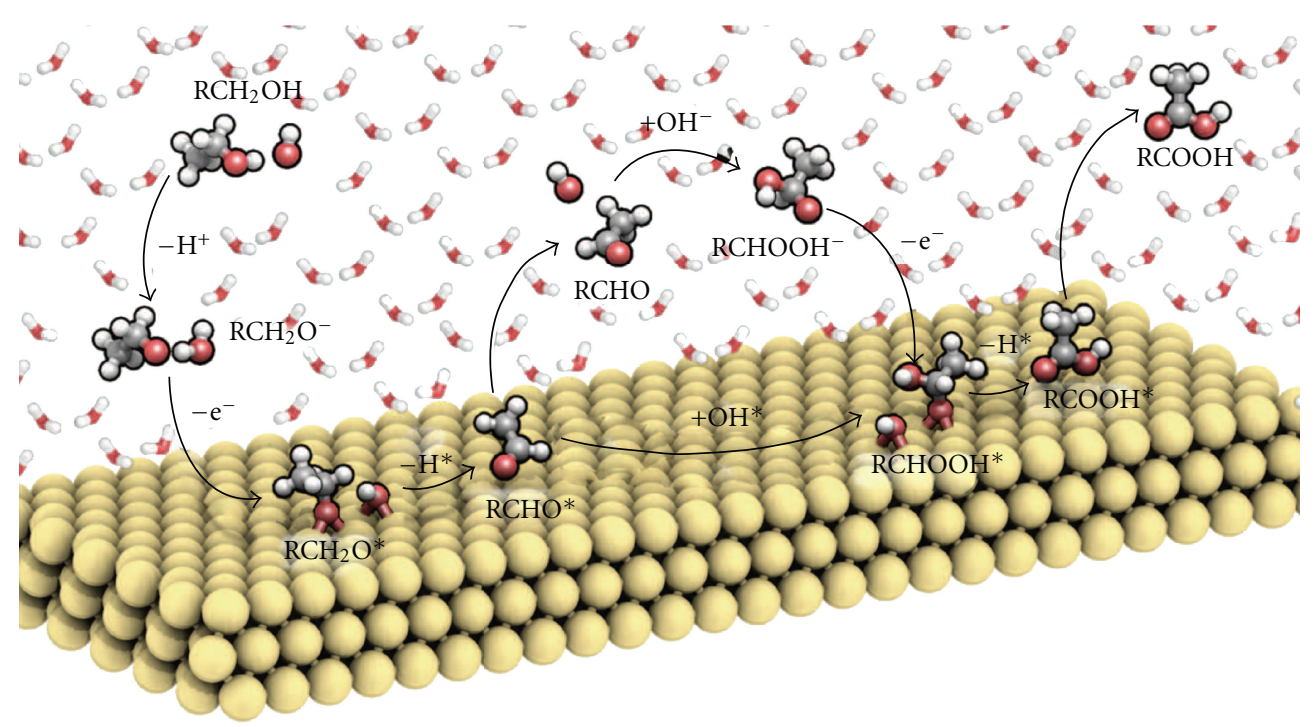

FIGURE 9: Schematic representaion of the reaction paths for ethanol and other polyol oxidation to acids over Au and Pt in alkaline media based on DFT results and isotopic kinetic labeling experiments. (Copyright Science [98]).

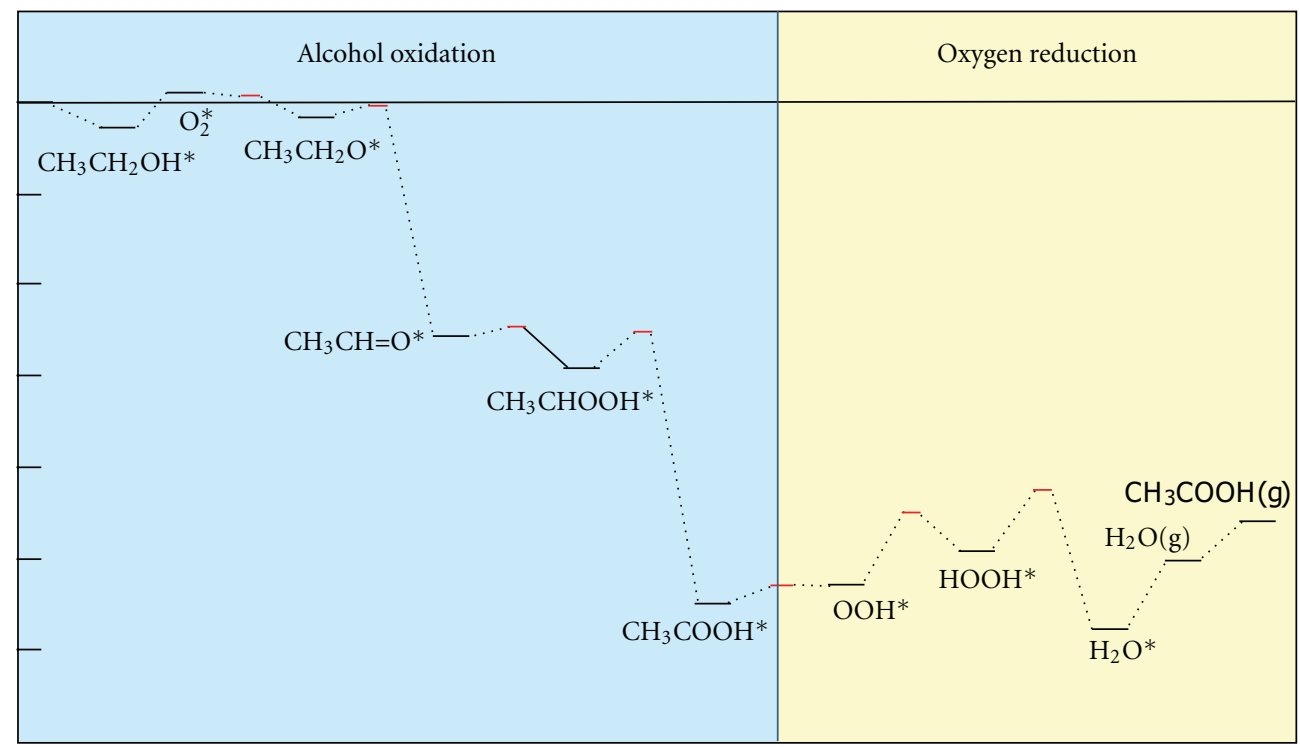

FIGURE 10: DFT-calculated potential energy surface for the catalytic oxidation of ethanol to acetic acid over Au(111) in the presence of base $\left(\mathrm{OH}^{-}\right)$and in water. Both the $\mathrm{OH}^{-}$as well as the metal are involved in the mechanism. In order establish an overall cycle, $\mathrm{O}_{2}$ is reduced via the electrons that from as a result of the oxidation of the alcohol as well as by the reaction protons that form upon the activation of water. Red lines refer to transition states, whereas the black lines refer to reaction intermediates.

the changes that result upon changing the $\mathrm{pH}$ and concentration.

While the oxidation of methanol as well as other alcohols can be carried out in acid media as was discussed above, the activity is rather low. The rates and currents increase significantly with increasing the $\mathrm{pH}$ of solution. The electrocatalytic oxidation of methanol as well as other alcohols over $\mathrm{Au}$ is quite high in alkaline media $[100,101,104-108,110$, $118,124-126]$. The higher rates and current densities found in alkaline media are the result of the high reactivity of $\mathrm{OH}^{-}$ anions that are weakly bound to the Au substrate at moderate potentials. The weakly bound hydroxyls are quite basic and will readily activate $\mathrm{C}-\mathrm{H}$ and $\mathrm{O}-\mathrm{H}$ bonds (on adsorbed species) as was presented above in the catalytic oxidation of alcohols over $\mathrm{Au}$ in basic media. The electrocatalytic activity over different $\mathrm{Au}$ substrates including polycrystalline $\mathrm{Au}$, $\mathrm{Au}(111)$, and $\mathrm{Au}(210)$ all show increases in activity with increases in the solution $\mathrm{pH}$ [101]. The adsorption of $\mathrm{OH}^{-}$ anions onto $\mathrm{Au}$ is thought to significantly enhance the reactivity of the surface over a range of potentials. Electrocatalytic oxidation can, therefore, proceed at much lower potentials where $\mathrm{Au}$ is not oxidized. 
The anodic oxidation of methanol begins to occur with the adsorption of $\mathrm{OH}^{-}$. In general, there are two very different regimes that result for methanol oxidation over Au [101]. In the first regime, methanol is actively oxidized by adsorbed $\mathrm{OH}^{-}$intermediates on $\mathrm{Au}$ at potentials as low as 0.6 V RHE. The second regime which occurs at much more positive potentials and results in the formation of $\mathrm{Au}-\mathrm{O}$ monolayers which are much less active for carrying out oxidation.

Chen and Lipkowski [127] and Yan et al. [107] provided more details in terms of the changes that take place at the surface as a result of these changes in potential and suggest that there are actually three regimes that result upon increasing the potential. The initial oxidation of methanol and other alcohols proceeds quite readily from $0.07-0.13 \mathrm{~V}$ versus $\mathrm{Hg} / \mathrm{HgO}$. The current increases linearly with the adsorption of $\mathrm{OH}^{-}$in this regime. There appears to be a weak amount of charge transfer between the $\mathrm{OH}^{-}$and the metal surface. The second regime appears between 0.13$0.3 \mathrm{~V}$ versus $\mathrm{Hg} / \mathrm{HgO}$ and results in a higher degree of charge transfer of $\mathrm{OH}$ and the Au sites in the surface. Regime 3 which appears at potentials greater than $0.3 \mathrm{~V} \mathrm{Hg} / \mathrm{HgO}$ is the inactive monolayer $\mathrm{Au}$ oxide that results. The oxidation of methanol is thought to proceed via the weakly held $\mathrm{OH}^{-}$ intermediates found in both regimes 1 and 2. The more strongly held oxygen intermediates which begin to form in regime 2 are less active. Regime 3 leads to the formation of monolayer Au oxide coverages and thus the loss of the active $\mathrm{OH}^{-}$sites. For methanol oxidation, the reaction is 0.75 order in methanol and 0.55 order in $\mathrm{OH}$ [107]. There is a clear negative shift in the potential and an increase in the current density with an increase in the concentration of weakly adsorbed $\mathrm{OH}^{\delta-}$ and methanol coverage.

3.3.3. Ethanol Oxidation over Au. Ethanol oxidation is similar to methanol oxidation in that there is a significant shift to lower potentials and increased current that results upon increasing $\mathrm{pH}$. Ethanol oxidation proceeds at a potential of $0.6 \mathrm{~V}$ versus RHE in alkaline solution which is $0.3 \mathrm{~V}$ lower than that reported in acid [115]. In addition there is a shift of $-0.1 \mathrm{~V}$ in the maximum from $1.35 \mathrm{~V}$ to $1.25 \mathrm{~V}$. The current density in alkaline media is found to be over an order of magnitude higher than that in neutral or acid conditions [115]. Regardless of the potential or $\mathrm{pH}$ there is negligible $\mathrm{C}-\mathrm{C}$ bond breaking that occurs on $\mathrm{Au}$, and as such, there is very little to no $\mathrm{CO}_{2}$ formation. The mechanism is thought to be very similar to the path outlined in Figure 10 and presented above for the catalytic oxidation of ethanol. The main path involves the oxidation of ethanol to acetaldehyde through the activation of the acidic $\mathrm{O}-\mathrm{H}$ and $\mathrm{C}-\mathrm{H}$ bonds by weakly adsorbed hydroxyl intermediates on the Au surface. Acetaldehyde subsequently reacts with weakly held $\mathrm{OH}^{\delta-}$ intermediates via simple nucleophilic attack depending of $\mathrm{OH}^{\delta-}$ on the $\mathrm{C}=\mathrm{O}$ bond of the aldehyde to form the geminal diol intermediate which can further react with $\mathrm{OH}^{-}$to form acetic acid or adsorbed acetate in alkaline media.

3.3.4. Extension to Polyols. These same ideas have been further extended to larger polyols such as glycerol and glucose in alkaline media [104-106, 125]. Glycerol, for example, reacts via a $4 \mathrm{e}^{-}$transfer process to form glyceric acid on both $\mathrm{Au}$ as well as Pt electrodes. At higher potentials, the $\mathrm{C}-\mathrm{C}$ bond of glyceric acid can further oxidize via a two electron transfer step to form glycolic and formic acids [125]. While this occurs over both Au and Pt, the selectivity to the over-oxidized glycolic state is much higher on Au. This was thought to be due to the fact that Pt deactivates by the formation of a surface oxide intermediate at much lower potential $(0.9 \mathrm{~V})$ than that found on $\mathrm{Au}(\sim 1.3 \mathrm{~V})$ [125]. This results in much lower oxidation potentials and a much narrower window for the subsequent oxidation to proceed. Glyceric acid as well as glycolic acid can both undergo further oxidation on $\mathrm{Pt}$ to form tartronic as well as oxalic acid, respectively. The subsequent $\mathrm{OH}^{-}$addition steps, however, only appear to proceed over $\mathrm{Pt}$ as neither of the di-substituted products appear over Au. The results reported by Kwon and Koper [125] for the electrocatalytic oxidation of glycerol discussed here are very similar to those reported by Ketchie et al. [78] for the catalytic oxidation of glycerol. Both show that C-C bond breaking steps can readily take place in the presence of $\mathrm{OH}^{-}$to form glycolic, formic, and oxalic acids on $\mathrm{Au}$ as well as on Pt. Both also reveal that Au will only oxidize one of the terminal $-\mathrm{CH}_{2} \mathrm{OH}$ bonds of the polyol, whereas Pt can oxidize both. It is very likely that the detailed mechanism for the formation of glyceric acid established for catalytic systems holds also for the electrocatalytic oxidation. The elementary steps involved in $\mathrm{C}-\mathrm{C}$ bond breaking are not known for either the catalytic or the electrocatalytic paths. The catalytic routes have been speculated to occur via oxidation with hydrogen peroxide or by base catalyzed paths. There is no evidence, however, for the formation of hydrogen peroxide electrocatalytically and more likely the reaction proceeds solely via the reaction with base.

The similarities and differences between the catalytic and electrocatalytic oxidation of alcohols is very informative. A closer analysis between the two suggests that the two are nearly equivalent with the exception that oxidation of the alcohol which occurs at the anode is decoupled from the oxygen reduction which occurs at the cathode. The two electrodes communicate via charge and ion transfer. In the heterogeneous catalytic system, the alcohol is oxidized where the electrons are directly used at the same aqueous metal interface to reduce $\mathrm{O}_{2}$. The rate of oxidation is thus directed by the rate at which $\mathrm{O}_{2}$ can be reduced by electrons. This is directly analogous to that which happens in the PEM alcohol fuel cells.

$\mathrm{CO}$ and alcohol oxidation make up just two reaction systems. One can readily draw analogies to other catalytic reaction systems carried out in aqueous media. Desai and Neurock for example carried out first principles DFT calculations to show that an aqueous medium could readily facilitate the catalytic hydrogenation of adsorbed oxygenates $[83,84,128]$. They showed that adsorbed hydrogen could undergo an electron transfer coupled with proton transfer at the metal interface to form a local proton in the form of a hydronium ion that could readily transfer through solution and attach itself with the negatively charged adsorbed surface intermediate. The solution phase here acts as a cocatalyst. As such, the solution provides for a short-circuited electrocatalytic cell 
which allows for electron and proton generation transfer and facile recombination. The ability carry out this heterolytic proton transfer process is controlled by the work function or "electron affinity" of the metal. Metals such as Pd and Pt should have the ability to convert adsorbed hydrogen into protons that reside in solution and electrons which remain in the metal. This was demonstrated by both Wagner and Moylan [129] and Kizhakevariam and Struve [130] who both showed that adsorbed hydrogen on ideal Pt substrates in the presence of water in UHV (at low temperature) forms hydronium ions in solution near the surface. These results are consistent with the results from theory. More generally the results suggest that the presence of protic media along with high work function metals can carry out hydrogenation reactions much more efficiently through proton coupled electron transfer processes that mimic electrocatalysis.

\section{Summary}

While fundamental information concerning reaction mechanisms, active sights and catalytic kinetics gleaned from in situ spectroscopy, detailed theoretical simulations and rigorous kinetic studies for gas phase heterogeneous catalysis has helped guide the development of electrocatalytic systems, the complexity of the reaction environment has often precluded more in-depth or quantitative analyses. The tremendous advances in spectroscopy along with theory, that have taken place over the past few decades, however, have allowed for more detailed resolution of the molecular transformations that occur in electrocatalytic systems along with a more detailed following of the nature of the active centers and their environment. There appears to be an important and growing trend where this knowledge and guiding principles from electrocatalysis are being used to guide heterogeneous the complex aqueous and solvent-based catalytic processes. The knowledge of the complex electrified interface in electrocatalysis bears a number of common similarities to the aqueous/metal interface for catalytic reactions carried out the presence of solution. More detailed fundamental studies which attempt to rigorously compare heterogeneous catalysis in solution with electrocatalysis will continue and will likely be crucial in establishing the links between the two.

\section{Acknowledgments}

A. Wieckowski gratefully acknowledges support from the National Science Foundation under Grant no. NSF CHE0651083 A. Wieckowski and ARO under Grant no. W911NF08-1-0309. M. Neurock gratefully acknowledges support from the Office of Basic Energy Sciences under Award no. ERKCC61 for the work on metal/solution interfaces. (This work is part of the Fluid Interface Reactions, Structures and Transport (FIRST) Center, an Energy Frontier Research Center funded by the U.S. Department of Energy, Office of Science, Office of Basic Energy Sciences), U.S. Department of Energy, Division of Chemical Sciences, Office of Basic Energy Sciences (DE-FG02-07ER15894) for the work on oxygen reduction, the National Science Foundation Research
Center for Biorenewable Chemicals (EEC-0813570), and the National Science Foundation PIRE (NSF OISE-0730277) for the work on alcohol oxidation. M. Neurock would also kindly acknowledge the computational time at the Environmental Molecular Science Laboratory, a national scientific user facility sponsored by the Department of Energy's Office of Biological and Environmental Research and located at Pacific Northwest National Laboratory, the National Center for Computational Sciences at Oak Ridge National Laboratory and the National Energy Research Scientific Computing Center, which is supported by the Office of Science of the U.S. Department of Energy which was used to carry out the work. Lastly, the authers would like to thank Professor Robert J. Davis, David Hibbitts, and Craig Plaisance for helpful discussions.

\section{References}

[1] D. Cao, G. Q. Lu, A. Wieckowski, S. A. Wasileski, and M. Neurock, "Mechanisms of methanol decomposition on platinum: a combined experimental and ab initio approach," Journal of Physical Chemistry B, vol. 109, no. 23, pp. 11622-11633, 2005.

[2] M. J. Janik, S. A. Wasileski, C. D. Taylor, and M. Neurock, "First principles simulation of the active sites and reaction environment in electrocatalysis," in Fuel Cell Catalysis: A Surface Science Approach, M. Koper, Ed., John Wiley and Sons, 2008.

[3] M. Koper, Ed., Fuel Cell Catalysis: A Surface Science Approach, John Wiley and Sons, 2008.

[4] A. Wieckowski and J. K. Nørskov, Fuel Cell Science: Theory, Fundamentals, and Bio-Catalysis, John Wiley and Sons, 2010.

[5] R. A. van Santen and M. Neurock, "Theory of surface chemical reactivity," in Handbook of Catalysis, H. K. G. Ertl and J. Weitcamp, Eds., pp. 942-958, Springer, 1997.

[6] R. A. van Santen and M. Neurock, Molecular Heterogeneous Catalysis: A Mechanistic and Computational Approach, $\mathrm{VCH}-$ Wiley, 2006.

[7] R. A. van Santen, M. Neurock, and S. G. Shetty, "Reactivity theory of transition-metal surfaces: a brønsted-evanspolanyi linear activation energy-free-energy analysis," Chemical Reviews, vol. 110, no. 4, pp. 2005-2048, 2010.

[8] T. Bligaard and J. K. Nørskov, "Ligand effects in heterogeneous catalysis and electrochemistry," Electrochimica Acta, vol. 52, no. 18, pp. 5512-5516, 2007.

[9] J. Greeley, T. F. Jaramillo, J. Bonde, I. B. Chorkendorff, and J. K. Nørskov, "Computational high-throughput screening of electrocatalytic materials for hydrogen evolution," Nature Materials, vol. 5, no. 11, pp. 909-913, 2006.

[10] P. Liu, A. Logadottir, and J. K. Nørskov, "Modeling the electro-oxidation of $\mathrm{CO}$ and $\mathrm{H}_{2} / \mathrm{CO}$ on $\mathrm{Pt}, \mathrm{Ru}, \mathrm{PtRu}$ and $\mathrm{Pt}_{3} \mathrm{Sn}$," Electrochimica Acta, vol. 48, no. 25-26, pp. 37313742, 2003.

[11] J. K. Nørskov, J. Rossmeisl, A. Logadottir et al., "Origin of the overpotential for oxygen reduction at a fuel-cell cathode," Journal of Physical Chemistry B, vol. 108, no. 46, pp. 1788617892, 2004.

[12] J. Rossmeisl, J. K. Nørskov, C. D. Taylor, M. J. Janik, and M. Neurock, "Calculated phase diagrams for the electrochemical oxidation and reduction of water over $\mathrm{Pt}(111)$," Journal of Physical Chemistry B, vol. 110, no. 43, pp. 21833-21839, 2006.

[13] A. B. Anderson, " $\mathrm{O}_{2}$ reduction and $\mathrm{CO}$ oxidation at the Ptelectrolyte interface. The role of $\mathrm{H}_{2} \mathrm{O}$ and $\mathrm{OH}$ adsorption 
bond strengths," Electrochimica Acta, vol. 47, no. 22-23, pp. 3759-3763, 2002.

[14] A. B. Anderson and Y. Cai, "Calculation of the Tafel plot for $\mathrm{H}_{2}$ oxidation on $\mathrm{Pt}(100)$ from potential-dependent activation energies," Journal of Physical Chemistry B, vol. 108, no. 52, pp. 19917-19920, 2004.

[15] A. B. Anderson, J. Roques, S. Mukerjee, V. S. Murthi, N. M. Markovic, and V. Stamenkovic, "Activation energies for oxygen reduction on platinum alloys: theory and experiment," Journal of Physical Chemistry B, vol. 109, no. 3, pp. 11981203, 2005.

[16] J. Roques and A. B. Anderson, "Electrode potential-dependent stages in $\mathrm{OH}_{a d s}$ formation on the $\mathrm{Pt}_{3} \mathrm{Cr}$ alloy (111) surface," Journal of the Electrochemical Society, vol. 151, no. 11, pp. E340-E347, 2004.

[17] J. Roques, A. B. Anderson, V. S. Murthi, and S. Mukerjee, "Potential shift for $\mathrm{OH}(\mathrm{ads})$ formation on the Pt skin on $\mathrm{Pt}_{3} \mathrm{Co}(111)$ electrodes in acid theory and experiment," Journal of the Electrochemical Society, vol. 152, no. 6, pp. E193E199, 2005.

[18] R. A. Sidik and A. B. Anderson, "Density functional theory study of $\mathrm{O}_{2}$ electroreduction when bonded to a Pt dual site," Journal of Electroanalytical Chemistry, vol. 528, no. 1-2, pp. 69-76, 2002.

[19] A. Lamm, H. Gasteiger, and W. Vielstich, Eds., Fuel Cell Handbook, Vol. 2, Electrocatalysis, Wiley-VCH, 2003.

[20] T. D. Jarvi and E. M. Stuve, "Fundamental aspects of vacuum and electrocatalytic reactions of methanol and formic acid on platinum surfaces," in Electrocatalysis, J. Lipkowski and P. N. Ross, Eds., Wiley-VCH, 1998.

[21] G. Q. Lu, A. Lagutchev, D. D. Dlott, and A. Wieckowski, "Quantitative vibrational sum-frequency generation spectroscopy of thin layer electrochemistry: CO on a Pt electrode," Surface Science, vol. 585, no. 1-2, pp. 3-16, 2005.

[22] P. K. Babu, H. S. Kim, S. T. Kuk et al., "Activation of nanoparticle Pt-Ru fuel cell catalysts by heat treatment: A195Pt NMR and electrochemical study," Journal of Physical Chemistry B, vol. 109, no. 36, pp. 17192-17196, 2005.

[23] H. Yano, J. Inukai, H. Uchida et al., "Particle-size effect of nanoscale platinum catalysts in oxygen reduction reaction: an electrochemical and ${ }_{195} \mathrm{Pt}$ EC-NMR study," Physical Chemistry Chemical Physics, vol. 8, no. 42, pp. 4932-4939, 2006.

[24] T. Kobayashi, P. K. Babu, J. H. Chung, E. Oldfield, and A. Wieckowski, "Coverage dependence of CO surface diffusion on Pt nanoparticles: an EC-NMR study," Journal of Physical Chemistry C, vol. 111, no. 19, pp. 7078-7083, 2007.

[25] S. Maniguet, R. J. Mathew, and A. E. Russell, "EXAFS of carbon monoxide oxidation on supported Pt fuel cell electrocatalysts," Journal of Physical Chemistry B, vol. 104, no. 9, pp. 1998-2004, 2000.

[26] J. McBreen and S. Mukerjee, "In situ X-ray absorption studies of a Pt-Ru electrocatalyst," Journal of the Electrochemical Society, vol. 142, no. 10, pp. 3399-3404, 1995.

[27] F. J. Scott, C. Roth, and D. E. Ramaker, "Kinetics of CO poisoning in simulated reformate and effect of Ru island morphology on PtRu fuel cell catalysts as determined by operando X-ray absorption near edge spectroscopy," Journal of Physical Chemistry C, vol. 111, no. 30, pp. 11403-11413, 2007.

[28] F. J. Scott, S. Mukerjee, and D. E. Ramaker, "CO coverage/ oxidation correlated with PtRu electrocatalyst particle morphology in $0.3 \mathrm{M}$ methanol by in situ XAS," Journal of the Electrochemical Society, vol. 154, no. 5, pp. A396-A406, 2007.
[29] C. Roth, N. Benker, T. Buhrmester et al., "Determination of $\mathrm{O}[\mathrm{H}]$ and $\mathrm{CO}$ coverage and adsorption sites on PtRu electrodes in an operating PEM fuel cell," Journal of the American Chemical Society, vol. 127, no. 42, pp. 14607-14615, 2005.

[30] G. Samjeske, A. Miki, S. Ye, and M. Osawa, "Mechanistic study of electrocatalytic oxidation of formic acid at platinum in acidic solution by time-resolved surface-enhanced infrared absorption spectroscopy," Journal of Physical Chemistry B, vol. 110, no. 33, pp. 16559-16566, 2006.

[31] G. Samjeske, A. Miki, and M. Osawa, "Electrocatalytic oxidation of formaldehyde on platinum under galvanostatic and potential sweep conditions studied by time-resolved surface-enhanced infrared spectroscopy," Journal of Physical Chemistry C, vol. 111, no. 41, pp. 15074-15083, 2007.

[32] A. B. Anderson, "Theory at the electrochemical interface: reversible potentials and potential-dependent activation energies," Electrochimica Acta, vol. 48, no. 25-26, pp. 37433749, 2003.

[33] A. B. Anderson, Y. Cai, R. A. Sidik, and D. B. Kang, "Advancements in the local reaction center electron transfer theory and the transition state structure in the first step of oxygen reduction over platinum," Journal of Electroanalytical Chemistry, vol. 580, no. 1, pp. 17-22, 2005.

[34] A. B. Anderson, N. M. Neshev, R. A. Sidik, and P. Shiller, "Mechanism for the electrooxidation of water to $\mathrm{OH}$ and $\mathrm{O}$ bonded to platinum: quantum chemical theory," Electrochimica Acta, vol. 47, no. 18, pp. 2999-3008, 2002.

[35] Y. Cai and A. B. Anderson, "The reversible hydrogen electrode: potential-dependent activation energies over platinum from quantum theory," Journal of Physical Chemistry B, vol. 108, no. 28, pp. 9829-9833, 2004.

[36] E. Santos, A. Lundin, K. Potting, P. Quaino, and W. Schmickler, "Model for the electrocatalysis of hydrogen evolution," Physical Review B, vol. 79, no. 23, Article ID 235436, 2009.

[37] E. Santos and W. Schmickler, "Electronic interactions decreasing the activation barrier for the hydrogen electrooxidation reaction," Electrochimica Acta, vol. 53, no. 21, pp. 6149-6156, 2008.

[38] F. Wilhelm, W. Schmickler, R. R. Nazmutdinov, and E. Spohr, "A model for proton transfer to metal electrodes," Journal of Physical Chemistry C, vol. 112, no. 29, pp. 10814-10826, 2008.

[39] J. S. Filhol and M. Neurock, "Elucidation of the electrochemical activation of water over Pd by first principles," Angewandte Chemie, vol. 45, no. 3, pp. 403-406, 2006.

[40] C. Taylor, R. G. Kelly, and M. Neurock, "First-principles calculations of the electrochemical reactions of water at an immersed $\mathrm{Ni}(111) / \mathrm{H}_{2} \mathrm{O}$ interface," Journal of the Electrochemical Society, vol. 153, no. 12, pp. E207-E214, 2006.

[41] C. D. Taylor and M. Neurock, "Theoretical insights into the structure and reactivity of the aqueous/metal interface," Current Opinion in Solid State and Materials Science, vol. 9, no. 1-2, pp. 49-65, 2005.

[42] C. D. Taylor, M. Neurock, and J. R. Scully, "First-principles investigation of the fundamental corrosion properties of a model $\mathrm{Cu}_{38}$ nanoparticle and the (111), (113) surfaces," Journal of the Electrochemical Society, vol. 155, no. 8, pp. C407-C414, 2008.

[43] C. D. Taylor, S. A. Wasileski, J. S. Filhol, and M. Neurock, "First principles reaction modeling of the electrochemical interface: consideration and calculation of a tunable surface potential from atomic and electronic structure," Physical Review B, vol. 73, no. 16, Article ID 165402, pp. 1-16, 2006. 
[44] M. Otani, I. Hamada, O. Sugino, Y. Morikawa, Y. Okamoto, and T. Ikeshoji, "Structure of the water/platinum interfacea first principles simulation under bias potential," Physical Chemistry Chemical Physics, vol. 10, no. 25, pp. 3609-3612, 2008.

[45] M. Otani, I. Hamada, O. Sugino, Y. Morikawa, Y. Okamoto, and T. Ikeshoji, "Electrode dynamics from first principles," Journal of the Physical Society of Japan, vol. 77, no. 2, Article ID 024802, 2008.

[46] R. Jinnouchi and A. B. Anderson, "Electronic structure calculations of liquid-solid interfaces: combination of density functional theory and modified Poisson-Boltzmann theory," Physical Review B, vol. 77, no. 24, Article ID 245417, 2008.

[47] J. Rossmeisl, E. Skulason, M. E. Bjorketun, V. Tripkovic, and J. K. Nørskov, "Modeling the electrified solid-liquid interface," Chemical Physics Letters, vol. 466, no. 1-3, pp. 6871, 2008.

[48] M. Neurock, W. Vielstich, H. A. Gasteiger, and H. Yokokawa, "First principles modeling for the electrooxidation of small molecules," in Handbook of Fuel Cells, W. Vielstich, H. A. Gasteiger, and H. Yokokawa, Eds., John Wiley and Sons, 2009.

[49] G. Kresse and J. Furthmuller, "Efficiency of ab-initio total energy calculations for metals and semiconductors using a plane-wave basis set," Computational Materials Science, vol. 6, no. 1, pp. 15-50, 1996.

[50] G. Kresse and J. Furthmuller, "Efficient iterative schemes for ab initio total-energy calculations using a plane-wave basis set," Physical Review B, vol. 54, no. 16, pp. 11169-11186, 1996.

[51] G. Henkelman and H. Jónsson, "Improved tangent estimate in the nudged elastic band method for finding minimum energy paths and saddle points," Journal of Chemical Physics, vol. 113, no. 22, pp. 9978-9985, 2000.

[52] G. Henkelman, B. P. Uberuaga, and H. Jónsson, "Climbing image nudged elastic band method for finding saddle points and minimum energy paths," Journal of Chemical Physics, vol. 113, no. 22, pp. 9901-9904, 2000.

[53] G. Henkelman and H. Jónsson, "A dimer method for finding saddle points on high dimensional potential surfaces using only first derivatives," Journal of Chemical Physics, vol. 111, no. 15 , pp. 7010-7022, 1999.

[54] R. R. Davda, J. W. Shabaker, G. W. Huber, R. D. Cortright, and J. A. Dumesic, "Aqueous-phase reforming of ethylene glycol on silica-supported metal catalysts," Applied Catalysis $B$, vol. 43, no. 1, pp. 13-26, 2003.

[55] P. Gallezot, N. Nicolaus, G. Fleche, and A. Perrard, "Glucose hydrogenation on ruthenium catalysts in a trickle-bed reactor," Journal of Catalysis, vol. 180, no. 1, pp. 51-55, 1998.

[56] D. K. Sohounloue, C. Montassier, and J. Barbier, "Catalytic hydrogenolysis of sorbitol," Reaction Kinetics and Catalysis Letters, vol. 22, no. 3-4, pp. 391-397, 1983.

[57] M. B. Valenzuela, C. W. Jones, and P. K. Agrawal, "Batch aqueous-phase reforming of woody biomass," Energy and Fuels, vol. 20, no. 4, pp. 1744-1752, 2006.

[58] N. Dimitratos, C. Messi, F. Porta, L. Prati, and A. Villa, "Investigation on the behaviour of $\mathrm{Pt}(0) /$ carbon and $\mathrm{Pt}(0)$, $\mathrm{Au}(0) /$ carbon catalysts employed in the oxidation of glycerol with molecular oxygen in water," Journal of Molecular Catalysis A, vol. 256, no. 1-2, pp. 21-28, 2006.

[59] R. D. Cortright, R. R. Davda, and J. A. Dumesic, "Hydrogen from catalytic reforming of biomass-derived hydrocarbons in liquid water," Nature, vol. 418, no. 6901, pp. 964-967, 2002.

[60] J. W. Shabaker, G. W. Huber, R. R. Davda, R. D. Cortright, and J. A. Dumesic, "Aqueous-phase reforming of ethylene glycol over supported platinum catalysts," Catalysis Letters, vol. 88, no. 1-2, pp. 1-8, 2003.

[61] E. P. Maris, W. C. Ketchie, V. Oleshko, and R. J. Davis, "Metal particle growth during glucose hydrogenation over $\mathrm{Ru} / \mathrm{SiO}_{2}$ evaluated by X-ray absorption spectroscopy and electron microscopy," Journal of Physical Chemistry B, vol. 110, no. 15, pp. 7869-7876, 2006.

[62] E. P. Maris, W. C. Ketchie, M. Murayama, and R. J. Davis, "Glycerol hydrogenolysis on carbon-supported PtRu and AuRu bimetallic catalysts," Journal of Catalysis, vol. 251, no. 2, pp. 281-294, 2007.

[63] W. C. Ketchie, E. P. Maris, and R. J. Davis, "In-situ X-ray absorption spectroscopy of supported $\mathrm{Ru}$ catalysts in the aqueous phase," Chemistry of Materials, vol. 19, no. 14, pp. 3406-3411, 2007.

[64] M. Haruta, T. Kobayashi, H. Sano, and N. Yamada, "Novel gold catalysts for the oxidation of carbon monoxide at a temperature far below 0.DEG.C," Chemistry Letters, vol. 16, no. 2, pp. 405-408, 1987.

[65] M. Haruta, N. Yamada, T. Kobayashi, and S. Iijima, "Gold catalysts prepared by coprecipitation for low-temperature oxidation of hydrogen and of carbon monoxide," Journal of Catalysis, vol. 115, no. 2, pp. 301-309, 1989.

[66] G. C. Bond, C. Louis, and D. T. Thompson, Catalysis by Gold, Imperial College Press, London, UK, 2006.

[67] R. Meyer, C. Lemire, S. K. Shaikhutdinov, and H. Freund, "Surface chemistry of catalysis by gold," Gold Bulletin, vol. 37, no. 1-2, pp. 72-124, 2004.

[68] M. Valden, X. Lai, and D. W. Goodman, "Onset of catalytic activity of gold clusters on titania with the appearance of nonmetallic properties," Science, vol. 281, no. 5383, pp. 16471650, 1998.

[69] N. Lopez, T. V. W. Janssens, B. S. Clausen et al., "On the origin of the catalytic activity of gold nanoparticles for lowtemperature CO oxidation," Journal of Catalysis, vol. 223, no. 1, pp. 232-235, 2004.

[70] Q. Fu, H. Saltsburg, and M. Flytzani-Stephanopoulos, “Active nonmetallic Au and Pt species on ceria-based water-gas shift catalysts," Science, vol. 301, no. 5635, pp. 935-938, 2003.

[71] J. Guzman and B. C. Gates, "Simultaneous presence of cationic and reduced gold in functioning $\mathrm{MgO}$-supported $\mathrm{CO}$ oxidation catalysts: evidence from X-ray absorption spectroscopy," Journal of Physical Chemistry B, vol. 106, no. 31, pp. 7659-7665, 2002.

[72] L. M. Molina and B. Hammer, "Active role of oxide support during $\mathrm{CO}$ oxidation at Au/MgO," Physical Review Letters, vol. 90, no. 20, 4 pages, 2003.

[73] C. K. Costello, M. C. Kung, H. S. Oh, Y. Wang, and H. H. Kung, "Nature of the active site for $\mathrm{CO}$ oxidation on highly active $\mathrm{Au} / \gamma-\mathrm{Al}_{2} \mathrm{O}_{3}$," Applied Catalysis A, vol. 232, no. 1-2, pp. 159-168, 2002.

[74] H. H. Kung, M. C. Kung, and C. K. Costello, "Supported $\mathrm{Au}$ catalysts for low temperature CO oxidation," Journal of Catalysis, vol. 216, no. 1-2, pp. 425-432, 2003.

[75] W. B. Kim, T. Voitl, G. J. Rodriguez-Rivera, and J. A. Dumesic, "Powering fuel cells with CO via aqueous polyoxometalates and gold catalysts," Science, vol. 305, no. 5688, pp. 1280 1283, 2004.

[76] M. A. Sanchez-Castillo, C. Couto, W. B. Kim, and J. A. Dumesic, "Gold-nanotube membranes for the oxidation of CO at gas-water interfaces," Angewandte Chemie, vol. 43, no. 9, pp. 1140-1142, 2004. 
[77] W. C. Ketchie, Y. L. Fang, M. S. Wong, M. Murayama, and R. J. Davis, "Influence of gold particle size on the aqueousphase oxidation of carbon monoxide and glycerol," Journal of Catalysis, vol. 250, no. 1, pp. 94-101, 2007.

[78] W. C. Ketchie, M. Murayama, and R. J. Davis, "Promotional effect of hydroxyl on the aqueous phase oxidation of carbon monoxide and glycerol over supported Au catalysts," Topics in Catalysis, vol. 44, no. 1-2, pp. 307-317, 2007.

[79] N. M. Markoví and P. N. Ross, "Surface science studies of model fuel cell electrocatalysts," Surface Science Reports, vol. 45, no. 4-6, pp. 117-229, 2002.

[80] F. B. de Mongeot, M. Scherer, B. Gleich, E. Kopatzki, and R. J. Behm, "CO adsorption and oxidation on bimetallic Pt/ $\mathrm{Ru}(0001)$ surfaces-a combined STM and TPD/TPR study," Surface Science, vol. 411, no. 3, pp. 249-262, 1998.

[81] H. A. Gasteiger, N. Markovic, P. N. Ross, and E. J. Cairns, "Electro-oxidation of small organic molecules on well-characterized PtRu alloys," Electrochimica Acta, vol. 39, no. 11-12, pp. 1825-1832, 1994.

[82] N. M. Markovic, H. A. Gasteiger, P. N. Ross, X. Jiang, I. Villegas, and M. J. Weaver, "Electro-oxidation mechanisms of methanol and formic acid on Pt-Ru alloy surfaces," Electrochimica Acta, vol. 40, no. 1, pp. 91-98, 1995.

[83] S. Desai and M. Neurock, "A first principles analysis of CO oxidation over Pt and Pt 66.7\%Ru33.3\% (111) surfaces," Electrochimica Acta, vol. 48, no. 25-26, pp. 3759-3773, 2003.

[84] S. K. Desai and M. Neurock, "First-principles study of the role of solvent in the dissociation of water over a Pt-Ru alloy," Physical Review B, vol. 68, no. 7, Article ID 075420, pp. 754201-754207, 2003.

[85] B. E. Hayden, D. Pletcher, M. E. Rendall, and J. P. Suchsland, "CO oxidation on gold in acidic environments: particle size and substrate effects," Journal of Physical Chemistry C, vol. 111, no. 45, pp. 17044-17051, 2007.

[86] B. E. Hayden, D. Pletcher, and J. P. Suchsland, "Enhanced activity for electrocatalytic oxidation of carbon monoxide on titania-supported gold nanoparticles," Angewandte Chemie, vol. 46, no. 19, pp. 3530-3532, 2007.

[87] J. L. Roberts and D. T. Sawyer, "Electrochemical oxidation of carbon monoxide at gold electrodes," Electrochimica Acta, vol. 10, no. 10, pp. 989-1000, 1965.

[88] P. Rodriguez, N. Garcia-Araez, and M. T. M. Koper, "Selfpromotion mechanism for CO electrooxidation on gold," Physical Chemistry Chemical Physics, vol. 12, no. 32, pp. 9373-9380, 2010.

[89] P. Rodriguez, N. Garcia-Araez, A. Koverga, S. Frank, and M. T. M. Koper, "CO electroxidation on gold in alkaline media: a combined electrochemical, spectroscopic, and DFT study," Langmuir, vol. 26, no. 14, pp. 12425-12432, 2010.

[90] I. X. Green, W. Tang, M. Neurock, and J. T. Yates Jr., "Spectroscopic observation of dual catalytic sites during oxidation of $\mathrm{CO}$ on a $\mathrm{Au} / \mathrm{TiO}_{2}$ catalyst," Science, vol. 333, no. 6043, pp. 736-739, 2011.

[91] M. Neurock, D. Hibbitts, and J. A. Dumesic, "Mechanistic insights into the role of water on the oxidation of $\mathrm{CO}$ over Au," to be submitted, 2011.

[92] N. Dimitratos, J. A. Lopez-Sanchez, J. M. Anthonykutty et al., "Oxidation of glycerol using gold-palladium alloy-supported nanocrystals," Physical Chemistry Chemical Physics, vol. 11, no. 25, pp. 4952-4961, 2009.

[93] N. Dimitratos, J. A. Lopez-Sanchez, S. Meenakshisundaram et al., "Selective formation of lactate by oxidation of 1,2propanediol using gold palladium alloy supported nanocrystals," Green Chemistry, vol. 11, no. 8, pp. 1209-1216, 2009.
[94] M. D. Hughes, Y. J. Xu, P. Jenkins et al., "Tunable gold catalysts for selective hydrocarbon oxidation under mild conditions," Nature, vol. 437, no. 7062, pp. 1132-1135, 2005.

[95] G. J. Hutchings, S. Carrettin, P. Landon et al., "New approaches to designing selective oxidation catalysts: $\mathrm{Au} / \mathrm{C}$ a versatile catalyst," Topics in Catalysis, vol. 38, no. 4, pp. 223230, 2006.

[96] M. Sankar, N. Dimitratos, D. W. Knight et al., "Oxidation of glycerol to glycolate by using supported gold and palladium nanoparticles," ChemSusChem, vol. 2, no. 12, pp. 1145-1151, 2009.

[97] B. N. Zope and R. J. Davis, "Influence of reactor configuration on the selective oxidation of glycerol over $\mathrm{Au} / \mathrm{TiO}_{2}$," Topics in Catalysis, vol. 52, no. 3, pp. 269-277, 2009.

[98] B. N. Zope, D. D. Hibbitts, M. Neurock, and R. J. Davis, "Reactivity of the gold/water interface during selective oxidation catalysis," Science, vol. 330, no. 6000, pp. 74-78, 2010.

[99] J. S. Spendelow, P. K. Babu, and A. Wieckowski, "Electrocatalytic oxidation of carbon monoxide and methanol on platinum surfaces decorated with ruthenium," Current Opinion in Solid State and Materials Science, vol. 9, no. 1-2, pp. 37-48, 2005.

[100] J. S. Spendelow and A. Wieckowski, "Electrocatalysis of oxygen reduction and small alcohol oxidation in alkaline media," Physical Chemistry Chemical Physics, vol. 9, no. 21, pp. 26542675, 2007.

[101] Z. Borkowska, A. Tymosiak-Zielinska, and G. Shul, "Electrooxidation of methanol on polycrystalline and single crystal gold electrodes," Electrochimica Acta, vol. 49, no. 8, pp. 1209-1220, 2004.

[102] P. Parpot, A. P. Bettencourt, A. M. Carvalho, and E. M. Belgsir, "Biomass conversion: attempted electrooxidation of lignin for vanillin production," Journal of Applied Electrochemistry, vol. 30, no. 6, pp. 727-731, 2000.

[103] P. Parpot, A. P. Bettencourt, G. Chamoulaud, K. B. Kokoh, and E. M. Belgsir, "Electrochemical investigations of the oxidation-reduction of furfural in aqueous medium-application to electrosynthesis," Electrochimica Acta, vol. 49, no. 3, pp. 397-403, 2004.

[104] P. Parpot, N. Nunes, and A. P. Bettencourt, "Electrocatalytic oxidation of monosaccharides on gold electrode in alkaline medium: structure-reactivity relationship," Journal of Electroanalytical Chemistry, vol. 596, no. 1, pp. 65-73, 2006.

[105] P. Parpot, S. G. Pires, and A. P. Bettencourt, "Electrocatalytic oxidation of D-galactose in alkaline medium," Journal of Electroanalytical Chemistry, vol. 566, no. 2, pp. 401-408, 2004.

[106] P. Parpot, P. R. B. Santos, and A. P. Bettencourt, "Electrooxidation of d-mannose on platinum, gold and nickel electrodes in aqueous medium," Journal of Electroanalytical Chemistry, vol. 610, no. 2, pp. 154-162, 2007.

[107] S. H. Yan, S. C. Zhang, Y. Lin, and G. R. Liu, "Electrocatalytic performance of gold nanoparticles supported on activated carbon for methanol oxidation in alkaline solution," Journal of Physical Chemistry C, vol. 115, no. 14, pp. 6986-6993, 2011.

[108] P. A. Christensen, A. Hamnett, and D. Linares-Moya, "Oxygen reduction and fuel oxidation in alkaline solution," Physical Chemistry Chemical Physics, vol. 13, no. 12, pp. 5206-5214, 2011.

[109] D. Kardash, C. Korzeniewski, and N. Markovic, "Effects of thermal activation on the oxidation pathways of methanol at bulk Pt-Ru alloy electrodes," Journal of Electroanalytical Chemistry, vol. 500, no. 1-2, pp. 518-523, 2001. 
[110] A. V. Tripkovi, K. D. Popovi, B. N. Grgur, B. Blizanac, P. N. Ross, and N. M. Markovi, "Methanol electrooxidation on supported Pt and PtRu catalysts in acid and alkaline solutions," Electrochimica Acta, vol. 47, no. 22-23, pp. 3707-3714, 2002.

[111] F. Colmati, G. Tremiliosi-Filho, E. R. Gonzalez, A. Berna, E. Herrero, and J. M. Feliu, "The role of the steps in the cleavage of the C-C bond during ethanol oxidation on platinum electrodes," Physical Chemistry Chemical Physics, vol. 11, no. 40, pp. 9114-9123, 2009.

[112] F. Colmati, G. Tremiliosi-Filho, E. R. Gonzalez, A. Berna, E. Herrero, and J. M. Feliu, "Surface structure effects on the electrochemical oxidation of ethanol on platinum single crystal electrodes," Faraday Discussions, vol. 140, pp. 379397, 2008.

[113] V. Del Colle, A. Berna, G. Tremiliosi-Filho, E. Herrero, and J. M. Feliu, "Ethanol electrooxidation onto stepped surfaces modified by $\mathrm{Ru}$ deposition: electrochemical and spectroscopic studies," Physical Chemistry Chemical Physics, vol. 10, no. 25, pp. 3766-3773, 2008.

[114] J. Souza-Garcia, E. Herrero, and J. M. Feliu, "Breaking the $\mathrm{C}-\mathrm{C}$ bond in the ethanol oxidation reaction on platinum electrodes: effect of steps and ruthenium adatoms," ChemPhysChem, vol. 11, no. 7, pp. 1391-1394, 2010.

[115] S. C. S. Lai, S. E. F. Kleijn, F. T. Z. Ozturk et al., "Effects of electrolyte $\mathrm{pH}$ and composition on the ethanol electrooxidation reaction," Catalysis Today, vol. 154, no. 1-2, pp. 92$104,2010$.

[116] S. C. S. Lai, S. E. F. Kleyn, V. Rosca, and M. T. M. Koper, "Mechanism of the dissociation and electrooxidation of ethanol and acetaldehyde on platinum as studied by SERS," Journal of Physical Chemistry C, vol. 112, no. 48, pp. 1908019087, 2008.

[117] S. C. S. Lai and M. T. M. Koper, "Electro-oxidation of ethanol and acetaldehyde on platinum single-crystal electrodes," Faraday Discussions, vol. 140, pp. 399-416, 2008.

[118] S. C. S. Lai and M. T. M. Koper, "Ethanol electro-oxidation on platinum in alkaline media," Physical Chemistry Chemical Physics, vol. 11, no. 44, pp. 10446-10456, 2009.

[119] S. C. S. Lai and M. T. M. Koper, "The influence of surface structure on selectivity in the ethanol electro-oxidation reaction on platinum," Journal of Physical Chemistry Letters, vol. 1, no. 7, pp. 1122-1125, 2010.

[120] M. Neurock, M. Janik, and A. Wieckowski, "A first principles comparison of the mechanism and site requirements for the electrocatalytic oxidation of methanol and formic acid over Pt," Faraday Discussions, vol. 140, no. 1, pp. 363-378, 2008.

[121] S. R. Brankovic, J. X. Wang, Y. Zhu, R. Sabatini, J. McBreen, and R. R. Adzic, "Electrosorption and catalytic properties of bare and Pt modified single crystal and nanostructured $\mathrm{Ru}$ surfaces," Journal of Electroanalytical Chemistry, vol. 524-525, pp. 231-241, 2002.

[122] T. Iwasita, "Electrocatalysis of methanol oxidation," Electrochimica Acta, vol. 47, no. 22-23, pp. 3663-3674, 2002.

[123] W. C. Ketchie, M. Murayama, and R. J. Davis, "Selective oxidation of glycerol over carbon-supported AuPd catalysts," Journal of Catalysis, vol. 250, no. 2, pp. 264-273, 2007.

[124] A. T. Governo, L. Proenca, P. Parpot, M. I. S. Lopes, and I. T. E. Fonseca, "Electro-oxidation of D-xylose on platinum and gold electrodes in alkaline medium," Electrochimica Acta, vol. 49, no. 9-10, pp. 1535-1545, 2004.

[125] Y. Kwon and M. T. M. Koper, "Combining voltammetry with HPLC: application to electro-oxidation of glycerol," Analytical Chemistry, vol. 82, no. 13, pp. 5420-5424, 2010.
[126] Z. W. Liu, F. Peng, H. J. Wang, H. Yu, W. X. Zheng, and J. A. Yang, "Phosphorus-doped graphite layers with high electrocatalytic activity for the $\mathrm{O}_{2}$ reduction in an alkaline medium," Angewandte Chemie, vol. 50, no. 14, pp. 3257-3261, 2011.

[127] A. C. Chen and J. Lipkowski, "Electrochemical and spectroscopic studies of hydroxide adsorption at the $\mathrm{Au}(111)$ electrode," Journal of Physical Chemistry B, vol. 103, no. 4, pp. 682-691, 1999.

[128] S. Desai, "Theoretical investigation of solution effects on metal catalyzed hydrogenation and oxidation processes," in Department of Chemical Engineering, University of Virginia, 2002.

[129] F. T. Wagner and T. E. Moylan, "Generation of surface hydronium from water and hydrogen coadsorbed on $\mathrm{Pt}(111)$," Surface Science, vol. 206, no. 1-2, pp. 187-202, 1988.

[130] N. Kizhakevariam and E. M. Stuve, "Coadsorption of water and hydrogen on $\mathrm{Pt}(100)$ : formation of adsorbed hydronium ions," Surface Science, vol. 275, no. 3, pp. 223-236, 1992. 


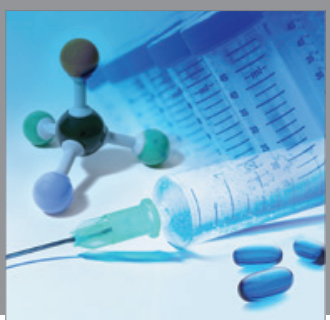

International Journal of

Medicinal Chemistry

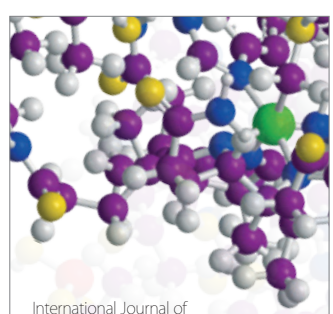

Carbohydrate Chemistry

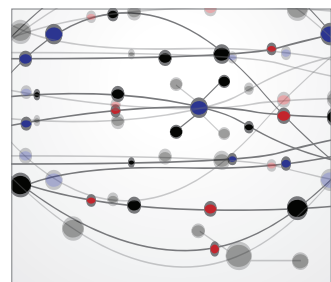

The Scientific World Journal
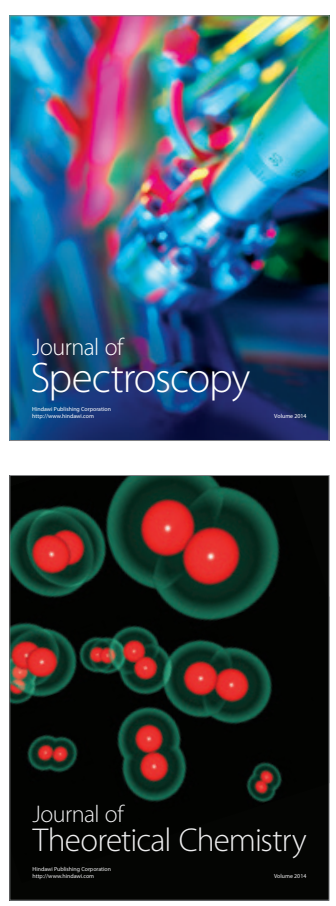
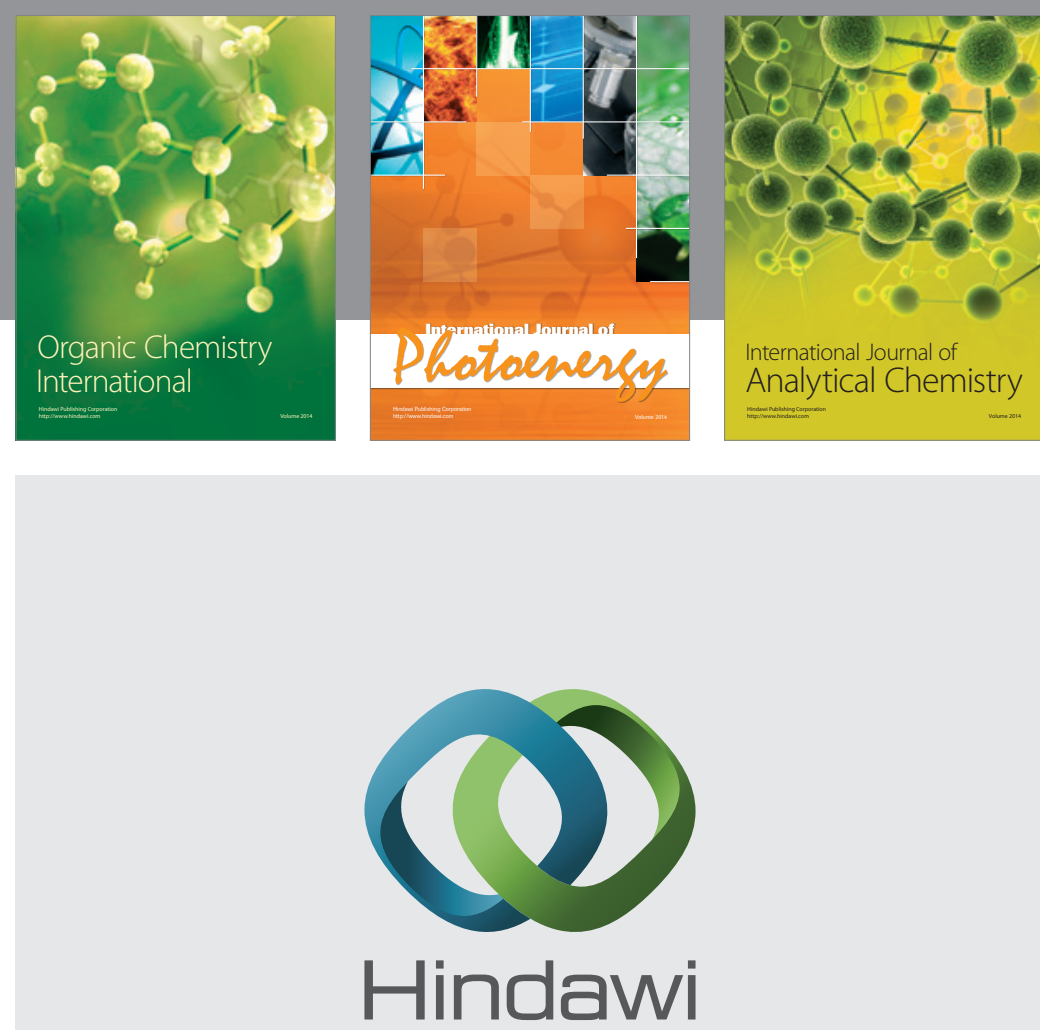

Submit your manuscripts at

http://www.hindawi.com
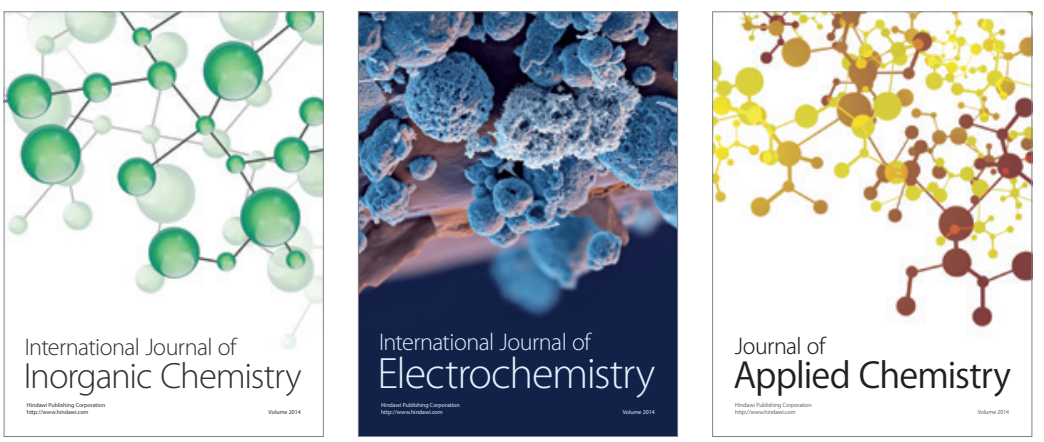

Journal of

Applied Chemistry
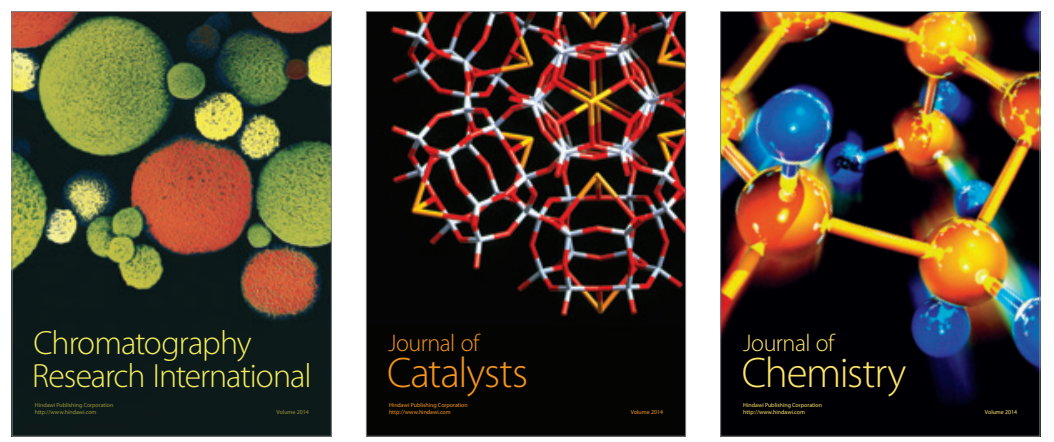
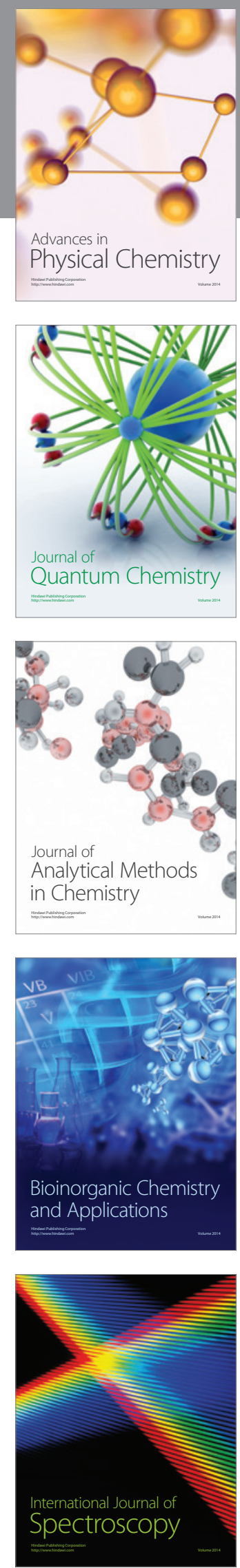